\title{
Processing thermogravimetric analysis data for isoconversional kinetic analysis of lignocellulosic biomass pyrolysis: Case study of corn stalk
}

\author{
Junmeng Cai ${ }^{1, *}$, Di Xu ${ }^{1}$, Zhujun Dong ${ }^{1}$, Xi Yu ${ }^{2}$, Yang Yang ${ }^{2}$, Scott W. Banks ${ }^{2}$, \\ Anthony V. Bridgwater ${ }^{2}$
}

${ }^{1}$ Biomass Energy Engineering Research Center, Key Laboratory of Urban Agriculture (South) Ministry of Agriculture, School of Agriculture and Biology, Shanghai Jiao Tong University, 800 Dongchuan Road, Shanghai 200240, People's Republic of China ${ }^{2}$ Bioenergy Research Group, European Bioenergy Research Institute (EBRI), Aston University, Birmingham B4 7ET, United Kingdom

Corresponding author: Junmeng Cai. Tel.: 0086-21-34206624; E-mail address: jmcai@sjtu.edu.cn

\begin{abstract}
:
Modelling of lignocellulosic biomass pyrolysis processes can be used to determine their key operating and design parameters. This requires significant amount of information about pyrolysis kinetic parameters, in particular the activation energy. Thermogravimetric analysis (TGA) is the most commonly used tool to obtain experimental kinetic data, and isoconversional kinetic analysis is the most effective way for processing TGA data to calculate effective activation energies for lignocellulosic biomass pyrolysis. This paper reviews the overall procedure of processing TGA data for isoconversional kinetic analysis of lignocellulosic biomass pyrolysis by using the Friedman isoconversional method. This includes the removal of "error" data points and dehydration stage from original TGA data, transformation of TGA data to conversion data, differentiation of conversion data and smoothing of derivative conversion data,
\end{abstract}


interpolation of conversion and derivative conversion data, isoconversional calculations, and reconstruction of kinetic process. The detailed isoconversional kinetic analysis of TGA data obtained from the pyrolysis of corn stalk at five heating rates were presented. The results have shown that the effective activation energies of corn stalk pyrolysis vary from 148 to $473 \mathrm{~kJ} \mathrm{~mol}^{-1}$ when the conversion ranges from 0.05 to 0.85 .

Key words: Thermogravimetric analysis (TGA); Kinetic analysis; Biomass Pyrolysis; Isoconversional kinetic method; Effective activation energy

\section{Graphical Abstract:}

Processing TGA Data for Isoconversional Kinetic Analysis

$\begin{gathered}\text { Step 1: } \\ \text { From TGA data to } \\ \text { conversion data }\end{gathered}$
$>$ Removal of "error" data
$\begin{gathered}\text { points } \\ \text { Removal of dehydration } \\ \text { stage }\end{gathered}$

\section{Introduction}

Lignocellulosic biomass can be used to produce renewable electricity, thermal energy, or biofuels, and chemicals via various conversion technologies, such as combustion, gasification, pyrolysis, bio-digestion, fermentation, etc. [1, 2]. The advantages that make biomass energy a perfect alternative to fossil fuels include: (1) it is a renewable form of energy; (2) it is carbon neutral; and (3) it is widely available. Lignocellulosic biomass pyrolysis, a thermochemical conversion process of heating lignocellulosic biomass in the absence of oxygen usually at $300-600{ }^{\circ} \mathrm{C}$, has the potential to offer high efficiencies for the production of liquid fuels which can be readily stored or transported $[3,4]$. The yields of those products are dependent upon the feedstock, thermal environment, heating rate and final pyrolysis reaction temperature [5-8]. Specifically, at a moderate pyrolysis reaction temperature (about $500{ }^{\circ} \mathrm{C}$ ) and 
under high heating rates, the main product is bio-oil $[9,10]$. Biomass pyrolysis can be performed through different types of pyrolysis reactors [11], such as fluidized bed [12], auger [13], rotary kiln [14], down-tube [15], and free fall reactors [16].

A comprehensive understanding of pyrolysis kinetics of a biomass feedstock is important to the process design, feasibility assessment and scaling in industrial applications [17-19]. Figure 1 shows a schematic flowchart for the overall process design of biomass pyrolysis. In general, the design of biomass pyrolysis processes requires hydrodynamics and transport simulation which involves information about mass and heat transfer as well as kinetics [20]. The optimal parameters for a pyrolysis process should meet the requirements of mass and heat transfer efficiency and pyrolysis kinetics [21, 22].

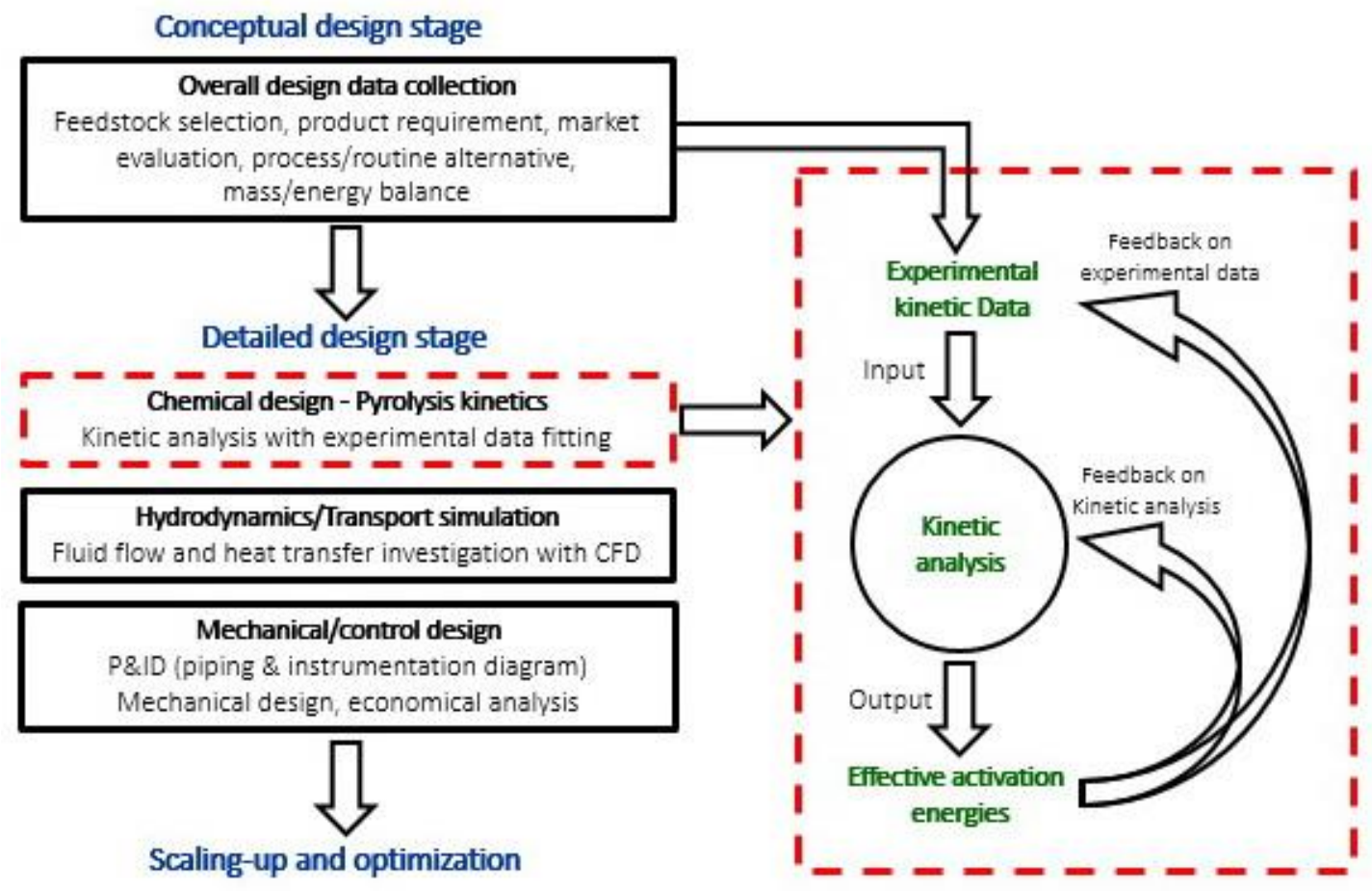

Figure 1. Flow chart of design of biomass pyrolysis processes.

Thermogravimetric analysis (TGA) is usually used for the kinetic analysis of lignocellulosic biomass pyrolysis. According to the search results based on two keywords "thermogravimetric analysis" and "biomass pyrolysis" from the Web of 
Science Database (http://isiknowledge.com), there are over 1,350 papers about biomass pyrolysis kinetic analysis by using TGA published in scientific journals indexed by SCI from 2000. Figure 2 shows the annual number of publications from 2000 to August, 2017, which indicates that TGA has been used to investigate the kinetic mechanism of lignocellulosic biomass pyrolysis by more and more researchers. Recently, Bach and Chen [23] provided a review on recent activities in pyrolysis characteristics and kinetics of various microalgae via TGA and pointed out that the kinetics via TGA was conductive to pyrolysis reactor design, operation optimization, and biofuel production. White et al. [24] concluded that many factors could affect the kinetic parameters based on the processing of TGA data, including process conditions, heat and mass transfer limitations, physical and chemical heterogeneity of the sample, and systematic errors. Saddawi et al. [25] focused on the data analysis method for extracting reliable kinetic data from TGA experiments.

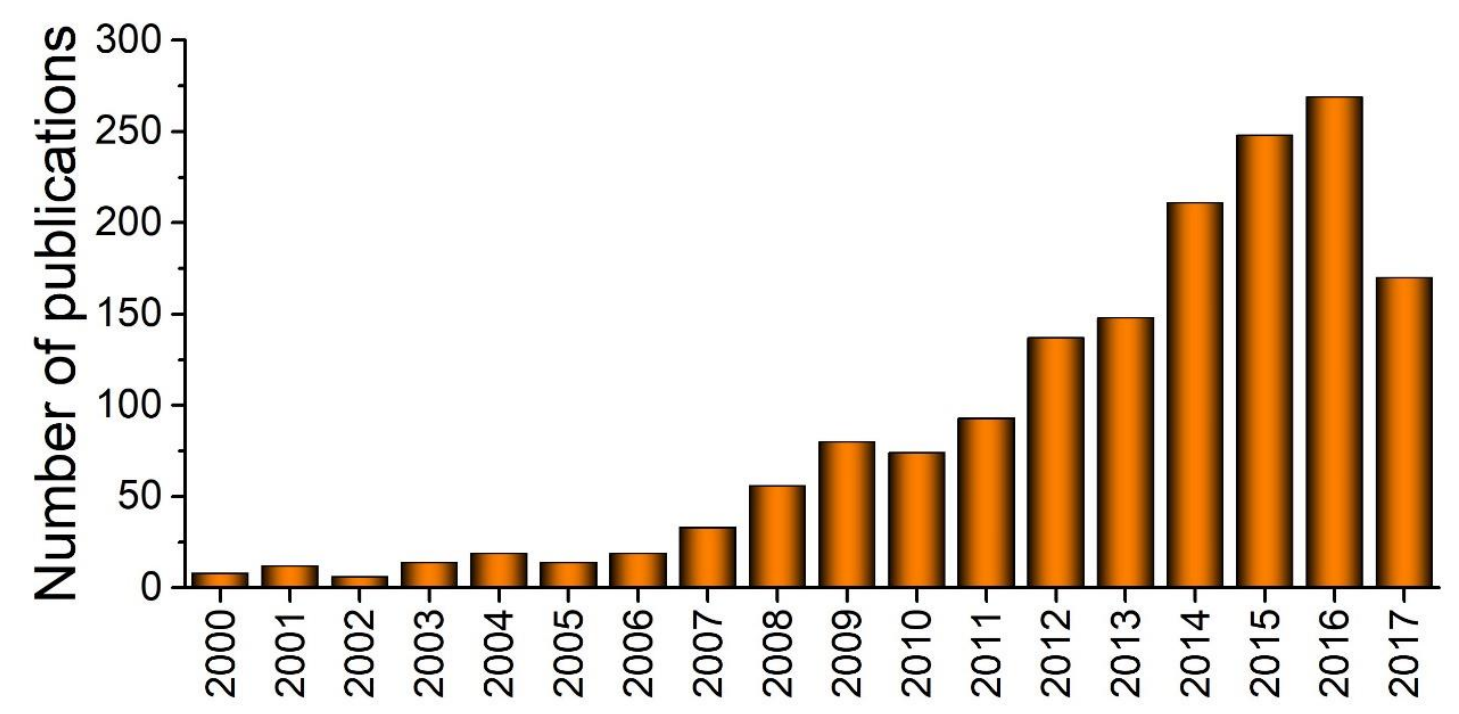

Figure 2. Number of annual publications from 2000 to present on "thermogravimetric analysis" and "biomass pyrolysis" (based on search results from Web of Knowledge Database).

There are two kinds of kinetic methods used for the analysis of biomass pyrolysis kinetics: model-fitting methods and isoconversional methods [26-28]. According to 
Sánchez-Jiménez et al. [29], the use of model-fitting methods may reach analogous conclusions: almost any conversion function can satisfactorily fit experimental data at the cost of estimating drastically different kinetic parameter values. The uncertainty in estimating kinetic parameters caused by the use of model-fitting methods can be avoided in the use of isoconversional methods.

There are many isoconversional kinetic methods including the Friedman differential isoconversional method [30], the Ozawa-Flynn-Wall linear integral isoconversional method [31, 32], the Kissinger-Akahira-Sunose linear integral isoconversional method [33], the Vyazovkin nonlinear integral isoconversional method [34], the advanced Vyazovkin nonlinear integral isoconversional method [35], and the Cai-Chen iterative linear integral isoconversional method [36]. The corresponding equations for obtaining the effective activation energies, advantages and disadvantages of various isoconversional methods are shown in Table 1. Of those isoconversional kinetic methods, the Friedman isoconversional method is the most widely used isoconversional method because its simplicity and high accuracy. Although the Friedman method is sensitive to data noise, the effect of noise on the isoconversional calculation can be reduced by considering not only data for a specific degree of conversion but also information in its neighborhood [37] or by applying some advanced smoothing methods [38].

When studying the kinetics of lignocellulosic biomass pyrolysis, the variation of activation energy with conversion obtained from isoconversional methods was frequently observed [39-44]. This variable activation energy was also called as the effective activation energy [45]. Processing TGA data is very important to obtain the effective activation energies for lignocellulosic biomass pyrolysis. Researchers have demonstrated some mathematical approaches about it. Caballero and Conesa [46] presented an overview of some relevant mathematical aspects involved in the thermal decomposition processes. Carrier et al. [47] summarized the data preparation and kinetic modeling of biomass pyrolysis by using the Friedman isoconversional method. Although they have discussed some aspects of processing TGA data for isoconversional 
kinetic analysis, a comprehensive study about the isoconversional kinetic analysis from TGA data of lignocellulosic biomass pyrolysis is still missing in the literature. Thus, the aim of this paper is to present the entire process of processing TGA data for isoconversional kinetic analysis of lignocellulosic biomass pyrolysis taking corn stalk pyrolysis as an example. 
Table 1. Advantages and disadvantages of various isoconversional methods

\begin{tabular}{|c|c|c|c|}
\hline Method & Equation & Obtaining $E_{\alpha}$ & Advantages and Disadvantages \\
\hline $\begin{array}{l}\text { Friedman } \\
\text { (FR) }\end{array}$ & $\ln \left[\beta_{i}\left(\frac{\mathrm{d} \alpha}{\mathrm{d} T}\right)_{\alpha, i}\right]=\ln \left[A_{\alpha} f(\alpha)\right]-\frac{E_{\alpha}}{R T_{\alpha, i}}$ & $\begin{array}{l}\text { For a given } \alpha \text {, the plot } \\
\ln \left[\beta_{i}(\mathrm{~d} \alpha / \mathrm{d} T)_{\alpha, i}\right] \quad \text { vs. } \\
\left(\mathrm{R} T_{\alpha, i}\right)^{-1} \text { should be a } \\
\text { straight line whose slope } \\
\text { can be used to estimate } \\
E_{\alpha} .\end{array}$ & $\begin{array}{l}\text { 1. The FR method is linear. } \\
\text { 2. The results obtained from the FR method are accurate. } \\
\text { 3. The FR method is not limited to the use of the linear variation } \\
\text { of the heating rate. } \\
\text { 4. The use of the FR method requires the derivative conversion } \\
\text { data, which would lead to be numerically unstable and noise } \\
\text { sensitive. }\end{array}$ \\
\hline $\begin{array}{l}\text { Ozawa- } \\
\text { Flynn-Wall } \\
\text { (OFW) }\end{array}$ & $\ln \beta_{i}=\ln \left[\frac{A_{\alpha} E_{\alpha}}{\operatorname{Rg}(\alpha)}\right]-5.331-1.052 \frac{E_{\alpha}}{R T_{\alpha, i}}$ & $\begin{array}{l}\text { For a given conversion } \\
\text { degree, the plot } \ln \beta_{i} \text { vs. - } \\
1.052\left(\mathrm{R} T_{a, i}\right)^{-1} \text { should be } \\
\text { a straight line whose } \\
\text { slope can be used to } \\
\text { evaluate } E_{\alpha} \text {. }\end{array}$ & $\begin{array}{l}\text { 1. The OFW method is linear. } \\
\text { 2. In the derivation of the OFW method, an oversimplified } \\
\text { temperature integral approximation is used. } \\
\text { 3. The OFW method was derived with the assumption of a } \\
\text { constant activation energy from the beginning of the reaction to } \\
\text { the conversion degree of interest. } \\
\text { 4. The use of the OFW method may lead to significant errors of } \\
E_{\alpha .}\end{array}$ \\
\hline $\begin{array}{l}\text { Kissinger- } \\
\text { Akahira- } \\
\text { Sunose } \\
\text { (KAS) }\end{array}$ & $\ln \left(\frac{\beta_{i}}{T_{\alpha, i}^{2}}\right)=\ln \left[\frac{R A_{\alpha}}{E_{\alpha} g(\alpha)}\right]-\frac{E_{\alpha}}{R T_{\alpha, i}}$ & $\begin{array}{l}\text { For a given conversion } \\
\text { degree, the plot of } \ln \left(\beta_{i}\right. \\
\left./ T_{\alpha, i}{ }^{2}\right) \quad \text { vs. } \quad-\left(\mathrm{R} T_{\alpha, i}\right)^{-1} \\
\text { should be a straight line } \\
\text { and its slope can be used } \\
\text { to evaluate } E_{\alpha} \text {. }\end{array}$ & $\begin{array}{l}\text { 1. The KAS method is linear. } \\
\text { 2. In the derivation of the KAS method, a oversimplified } \\
\text { temperature integral approximation is used. } \\
\text { 3. The KAS method was derived with the assumption of a } \\
\text { constant activation energy from the beginning of the reaction to } \\
\text { the conversion degree of interest. } \\
\text { 4. The use of the KAS method may lead to important errors of } \\
E_{\alpha} \text {. }\end{array}$ \\
\hline
\end{tabular}




\begin{tabular}{|c|c|c|c|}
\hline $\begin{array}{l}\text { Vyazovkin } \\
\text { nonlinear } \\
\text { method } \\
\text { (NL) }\end{array}$ & O.F. $=\sum_{i=1} \sum_{i \neq j}\left[\frac{\beta_{j} \int_{0}^{T_{\alpha, i}} e^{-E_{\alpha} / R T} \mathrm{~d} T}{\beta_{i} \int_{0}^{T_{\alpha, j}} e^{-E_{\alpha} / R T} \mathrm{~d} T}\right]$ & $\begin{array}{l}E_{\alpha} \text { is obtained by } \\
\text { minimizing of the O.F. }\end{array}$ & $\begin{array}{l}\text { 1. The NL method is free of temperature integral approximations } \\
\text { and is not limited to the use of the linear variation of the heating } \\
\text { rate. } \\
\text { 2. The NL method was derived with the assumption of a constant } \\
\text { activation energy from the beginning of the reaction to the } \\
\text { conversion degree of interest. } \\
\text { 3. The NL method is nonlinear. } \\
\text { 4. The use of the NL method may lead to some errors of } E_{\alpha} \text {. }\end{array}$ \\
\hline $\begin{array}{l}\text { Advanced } \\
\text { Vyazovkin } \\
\text { nonlinear } \\
\text { method } \\
\text { (ANL) }\end{array}$ & O.F. $=\sum_{i=1} \sum_{j \neq i} \frac{\beta_{j} \int_{T_{\alpha-\alpha, i}}^{T_{\alpha, i}} e^{-E_{\alpha} / R T} d T}{\beta_{i} \int_{T_{\alpha-\Delta \alpha, j}}^{T_{\alpha, j}} e^{-E_{\alpha} / R T} d T}$ & $\begin{array}{l}\text { Minimize the O.F. to } \\
\text { obtain } E_{\alpha} \text {. }\end{array}$ & $\begin{array}{l}\text { 1. The ANL method is free of temperature integral } \\
\text { approximations and is not limited to the use of the linear } \\
\text { variation of the heating rate. } \\
\text { 2. The results obtained from the ANL method are very close to } \\
\text { the true values. } \\
\text { 3. The ANL method is nonlinear. }\end{array}$ \\
\hline $\begin{array}{l}\text { Iterative } \\
\text { linear } \\
\text { integral } \\
\text { method } \\
\text { (Cai-Chen) }\end{array}$ & $\begin{array}{l}\ln \left\{\frac{\beta_{i}}{T_{\alpha, i}^{2}\left[h\left(x_{\alpha, i}\right)-\frac{x_{\alpha, i}^{2} e^{x_{\alpha, i}}}{x_{\alpha-\Delta \alpha, i}^{2} e^{\alpha_{\alpha-\Delta \alpha, i}}} h\left(x_{\alpha-\Delta \alpha, i}\right)\right]}\right\}=\ln \left[\frac{A_{\alpha-\Delta \alpha / 2} R}{E_{\alpha-\Delta \alpha / 2} g(\alpha, \alpha-\Delta \alpha)}\right]-\frac{E_{\alpha-\Delta \alpha / 2}}{R T_{\alpha, i}} \\
x_{\alpha}=\frac{E_{\alpha-\Delta \alpha / 2}}{R T_{\alpha}}, x_{\alpha-\Delta \alpha}=\frac{E_{\alpha-\Delta \alpha / 2}}{R T_{\alpha-\Delta \alpha}}, h(x)=x^{2} e^{x} \int_{x}^{\infty} \frac{e^{-x}}{x^{2}} \mathrm{~d} x\end{array}$ & $\begin{array}{l}\text { Obtain } E_{\alpha-\Delta \alpha / 2} \text { from the } \\
\text { slope of the plot of the } \\
\text { left hand side of the } \\
\text { equation vs. }-\left(\mathrm{R} T_{\alpha, i}\right)^{-1} \text {. } \\
\text { The left hand side of the } \\
\text { equation is calculated } \\
\text { from the last iterative } \\
\text { calculation value of } E_{\alpha-2} \\
\Delta \alpha / 2 \text {. }\end{array}$ & $\begin{array}{l}\text { 1. The Cai-Chen method is free of temperature integral } \\
\text { approximations. } \\
\text { 2. The Cai-Chen method is linear. } \\
\text { 3. The results obtained from the Cai-Chen method are very close } \\
\text { to the true values. }\end{array}$ \\
\hline
\end{tabular}




\section{TGA}

\subsection{Brief introduction of TGA}

TGA is a thermal analytical technique in which the changes in the mass of a sample is measured as a function of time or temperature as it is subjected to a controlled temperature program in a controlled atmosphere [48]. TGA can provide information about some chemical reactions or about some physical transitions [49]. According to our previous review [50], TGA can be used as an effective tool to perform the proximate analysis of solid fuels. A thermogravimetric analyzer usually consists of a sample pan that is supported by a precision balance [51]. The sample pan is placed in a furnace where the heating temperature and environment are controlled. The mass of the sample is continuously measured and recorded during the experiment.

By coupling a TGA instrument with evolved gas analysis (EGA) equipment, it is possible to detect and identify the evolved gas in a specific time in correlation with TGA signals. The main techniques currently include infrared (IR) analysis and mass spectroscopy (MS) [52, 53]. A more comprehensive TGA-GC/MS (gas chromatography/mass spectroscopy) technique involves separation of the evolving volatile species by GC and identification by MS [54]. In those techniques, the evolved gas from the TGA furnace is sampled either directly into spectrometer or is separated prior to further detection [55]. Through the application of those coupled techniques, the chemical compositions of released volatiles from biomass can be correlated to its lignocellulosic components [54].

Biomass pyrolysis is the thermal decomposition of biomass in the absence of oxygen. Therefore, in order to carry out the kinetic analysis of biomass pyrolysis using TGA, an inert purge gas (for example nitrogen, argon or helium) is chosen to control the atmosphere $[19,56]$. There are several heating programs can be used to perform the kinetic analysis of biomass pyrolysis using TGA: isothermal heating program [57], linear heating program [58] or stepwise linear heating program [59], as shown in Figure 3. 


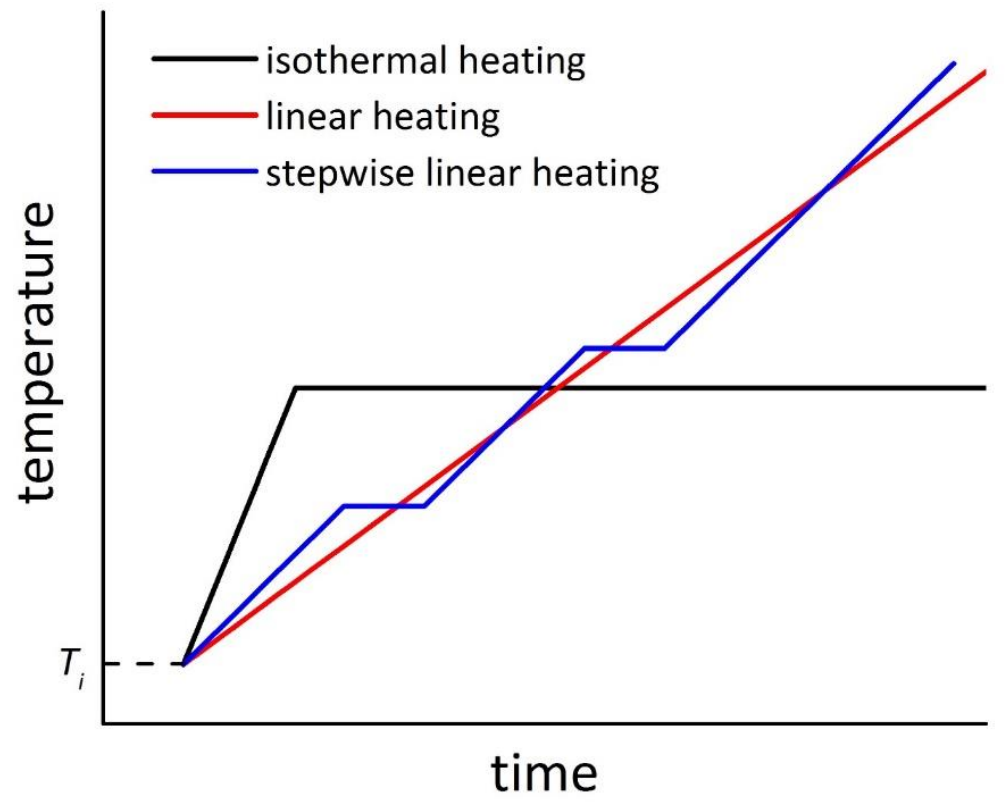

Figure 3. Heating program types for TGA.

The linear heating program is commonly used for biomass pyrolysis kinetics:

$$
T=T_{i}+\beta t
$$

where $T$ is the temperature, $T_{i}$ is the starting temperature, $t$ is the time, and $\beta$ is the heating rate.

In general, the heating rate used for biomass pyrolysis can range from 0.1 to 100 $\mathrm{K} \min ^{-1}[60]$, because mass transfer has an unwanted influence on TGA measurements when the heating rate is too high [61].

\subsection{TGA of corn stalk pyrolysis}

In this paper, a case study with corn stalk pyrolysis is performed to demonstrate the entire kinetic analysis process. The pyrolysis kinetics of corn stalk is carried out by a thermogravimetric analyzer (Pyris 1 TGA, PerkinElmer, USA) using an inert atmosphere of $\mathrm{N}_{2}$. The experiments are performed at five heating rates of 2.5, 5, 10, 20 and $40 \mathrm{~K} \mathrm{~min}^{-1}$. The results of proximate and ultimate analyses of the corn stalk sample 

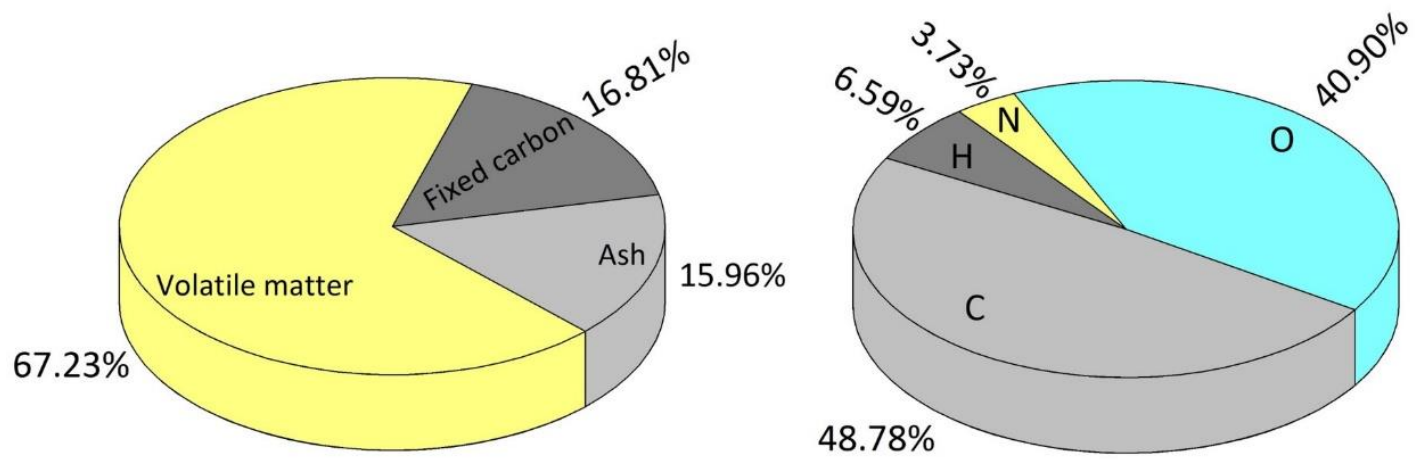

Figure 4. Proximate analysis result (dry basis) and ultimate analysis result (dry ash free basis) of corn stalk sample.

\section{From TGA data to conversion data}

\subsection{Removal of "error" data points of original TGA data}

Upon heating a biomass sample under inert atmosphere, its mass may decrease due to the water evaporation and the release of volatile matters during biomass pyrolysis. It is supposed that the mass versus time curve should show a decrease trend and each data point in the curve would be lower than the previous one. However, there are some data points against the decrease trend because of systematic errors [62]. In order to reduce possible effects caused by those "error" data points in further analysis, it is necessary to remove those "error" data points.

Carrier et al. [47] suggested the removal of zero and negative derivative conversion data points after smoothing and derivation of conversion data, which indicated that those "error" data points contained in the experimental TGA data would affect the later smoothing and derivation operation and the resulting derivative conversion data would contain many fluctuations. And the removal of some resulting derivative conversion data points would distort the data trend.

In this paper, a program is coded to perform the removal of "error" data points.

Figure 5 shows the flowchart of the program. 


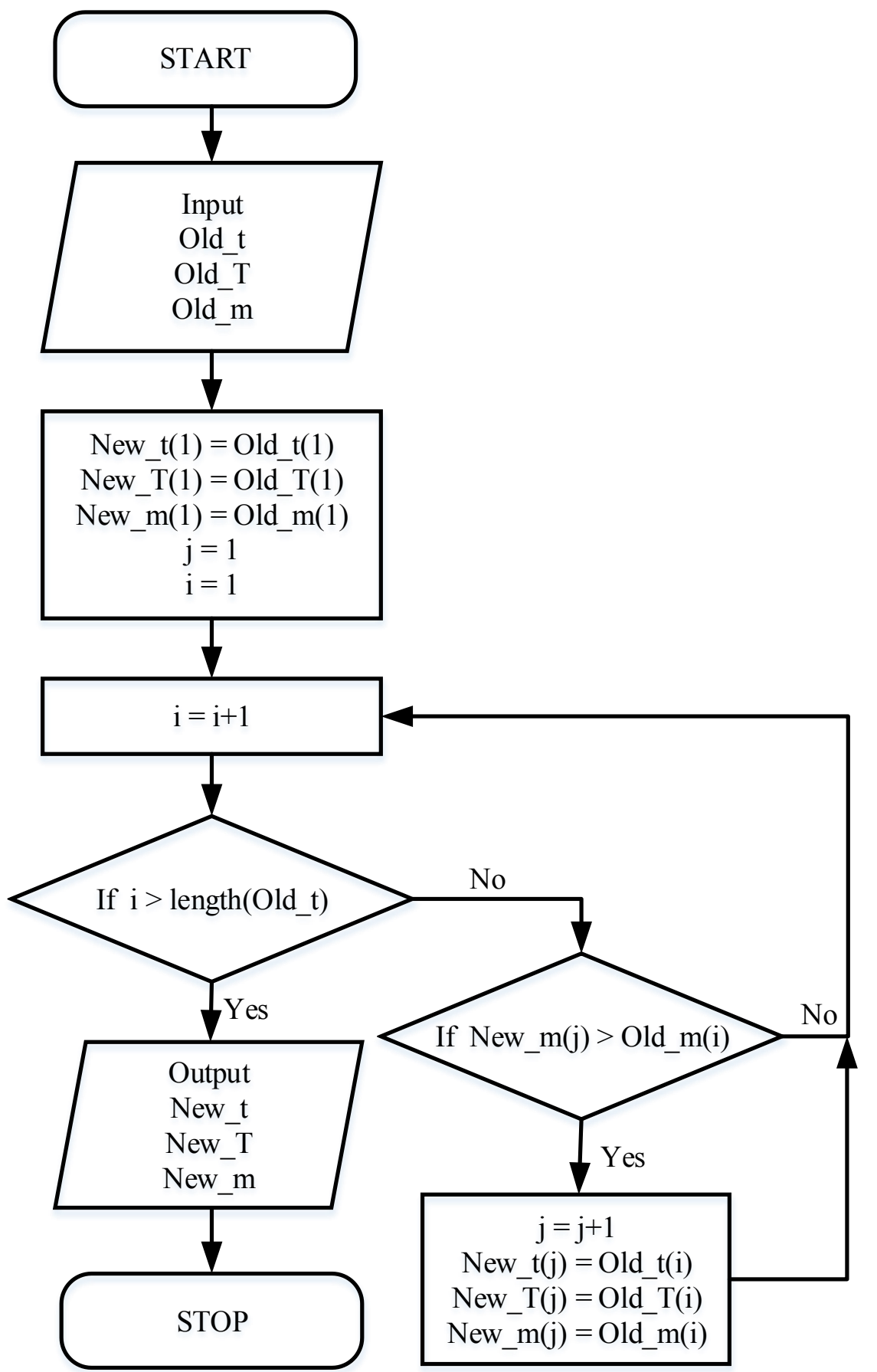

Figure 5. Flowchart of program for removal of "error" data points.

\subsection{Removal of dehydration stage from TGA data}

There are several stages in a lignocellulosic biomass pyrolysis process. The first stage is the dehydration stage $[63,64]$. The other stages correspond to the 
decomposition of biopolymer components (e.g. hemicellulose, cellulose, and lignin) of lignocellulosic biomass. The dehydration stage should be removed because the mechanisms of water evaporation in the dehydration stage and the decomposition of biopolymer components are different. In the study on the grape marc combustion kinetics [65], the dehydration stage was not removed, which led to large deviations of the model prediction from the experimental data.

In the removal of the dehydration stage, there is a problem of the determination of the range of the dehydration stage. The simplest way is to take a constant temperature as the end temperature $\left(T_{0}\right)$ of the dehydration stage. For example, Chen et al. [66] directly took $150{ }^{\circ} \mathrm{C}$ as the end temperature of the dehydration stage for the pyrolysis of corn stalk and wheat straw. In fact, the ASTM standard E1131 [67] provides a more accurate method. As shown in Figure 6, the center of the first mass loss plateau of the TGA curve ( $m-t$ curve) is considered as the end temperature of the dehydration stage. According to the standard [67], the mass loss plateau refers to a region of $m-t$ curve with a relatively constant mass.

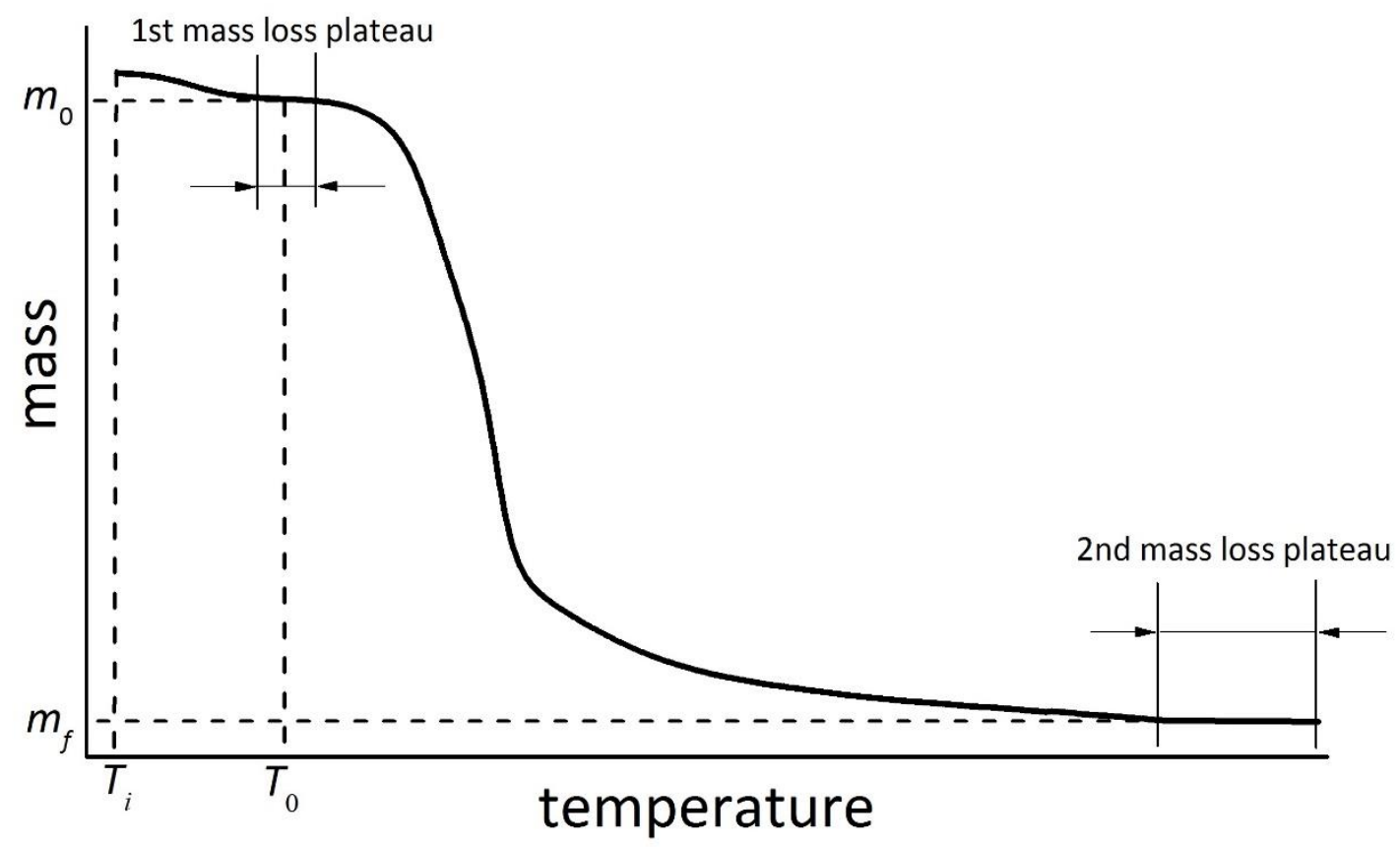

Figure 6. Schematic diagram of determination of $T_{0} m_{0}$, and $m_{f}$. 


\subsection{Determination of conversion}

The kinetic analysis of a chemical reaction is usually performed based on the degree of conversion [68]. Therefore, the obtained TGA data should be transferred to the form of the degree of conversion. The degree of conversion can be obtained based on the processed TGA curve:

$$
\alpha(T)=\frac{m_{0}-m(T)}{m_{0}-m_{f}}
$$

where $\alpha$ is the degree of conversion, $T$ is the temperature, $m_{0}$ is the mass at the temperature $T_{0}, m(T)$ is the mass at the temperature $T$, and $m_{f}$ is the final temperature.

Figure 6 also presents the determination of $m_{0}$ and $m_{f}$.

When $T$ increases from $T_{0}$ to $T_{f}, m$ decreases from $m_{0}$ to $m_{f}$, while $\alpha$ increases from 0 to 1, as shown in Figure 7.

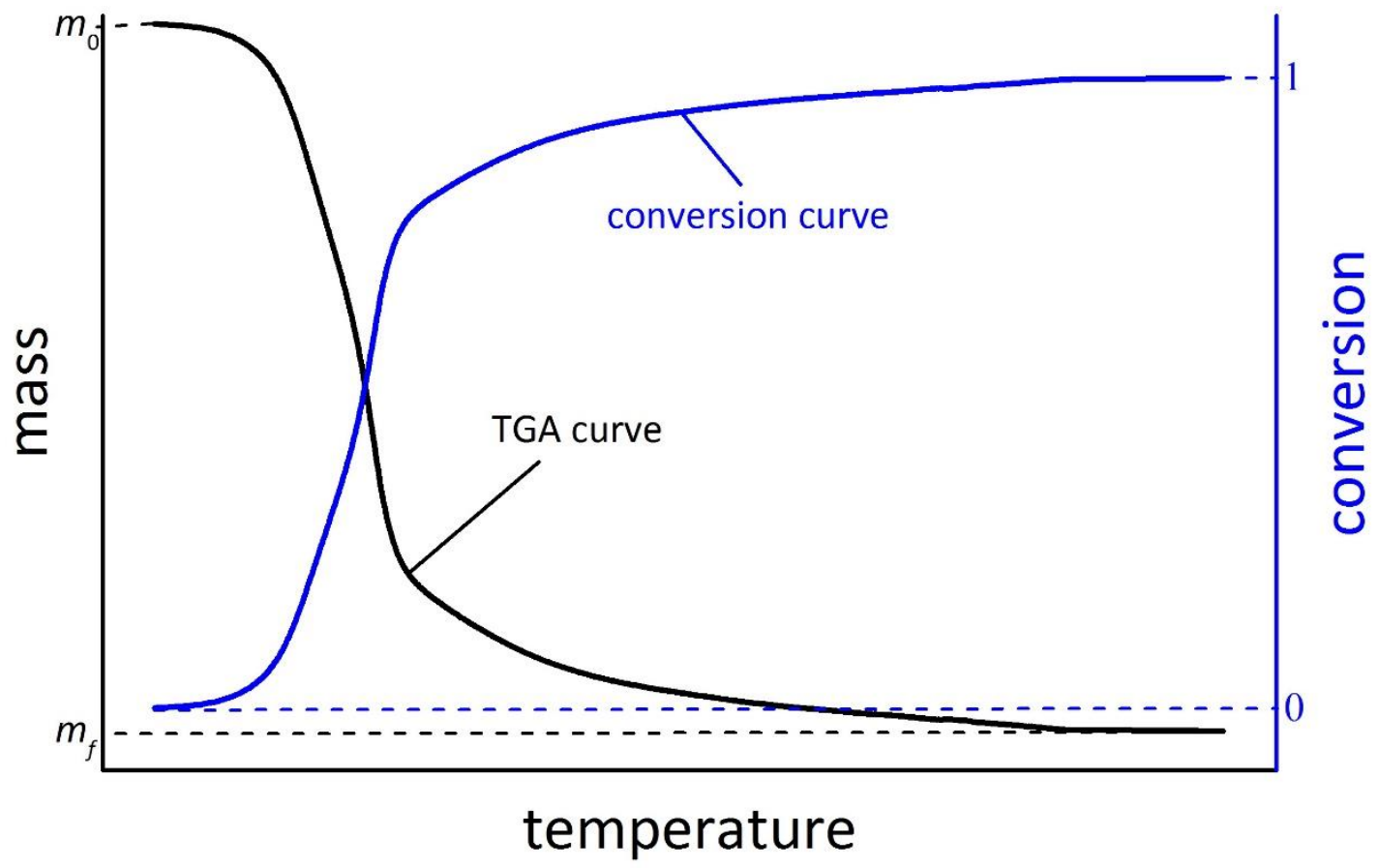

Figure 7. Schematic diagram of TGA and conversion curves. 


\section{Determination of smoothed derivative conversion data}

\subsection{Determination of derivative conversion}

The derivative conversion curve can give the information about the conversion rate, which may be more sensitive to revealing reaction details. In the kinetic analysis of biomass pyrolysis, the conversion rate information can be used to determine the overlapping pyrolysis reactions of biomass biopolymer components (e.g., cellulose, hemicellulose and lignin) $[69,70]$. And the derivative conversion data are required in the use of the Friedman differential isoconversional method.

The derivative conversion data are usually obtained from the numerical differentiation of the conversion data, which can be implemented by using the finite difference method. There are three forms of finite differences: forward, backward and central differences [71]. For the intermediate data points, the derivative conversion data are usually calculated by means of the central difference. The forward and backward differences are used for the estimation of the derivative conversion data of the start and end data points, respectively. The corresponding calculation formulae are listed below:

$$
\left(\frac{\mathrm{d} \alpha}{\mathrm{d} T}\right)_{i}=\left\{\begin{array}{cc}
\frac{\alpha_{i+1}-\alpha_{i}}{T_{i+1}-T_{i}} & \text { for start point } \\
\frac{1}{2} \frac{\alpha_{i}-\alpha_{i-1}}{T_{i}-T_{i-1}}+\frac{1}{2} \frac{\alpha_{i+1}-\alpha_{i}}{T_{i+1}-T_{i}} & \text { for intermediate points } \\
\frac{\alpha_{i}-\alpha_{i-1}}{T_{i}-T_{i-1}} & \text { for end point }
\end{array}\right.
$$

where $\alpha_{i}$ and $\left(\frac{\mathrm{d} \alpha}{\mathrm{d} T}\right)_{i}$ are the conversion and derivative conversion of the $i$ th point, respectively.

Figure 8 presents the flowchart of the numerical differentiation of conversion based on Equation (3). 


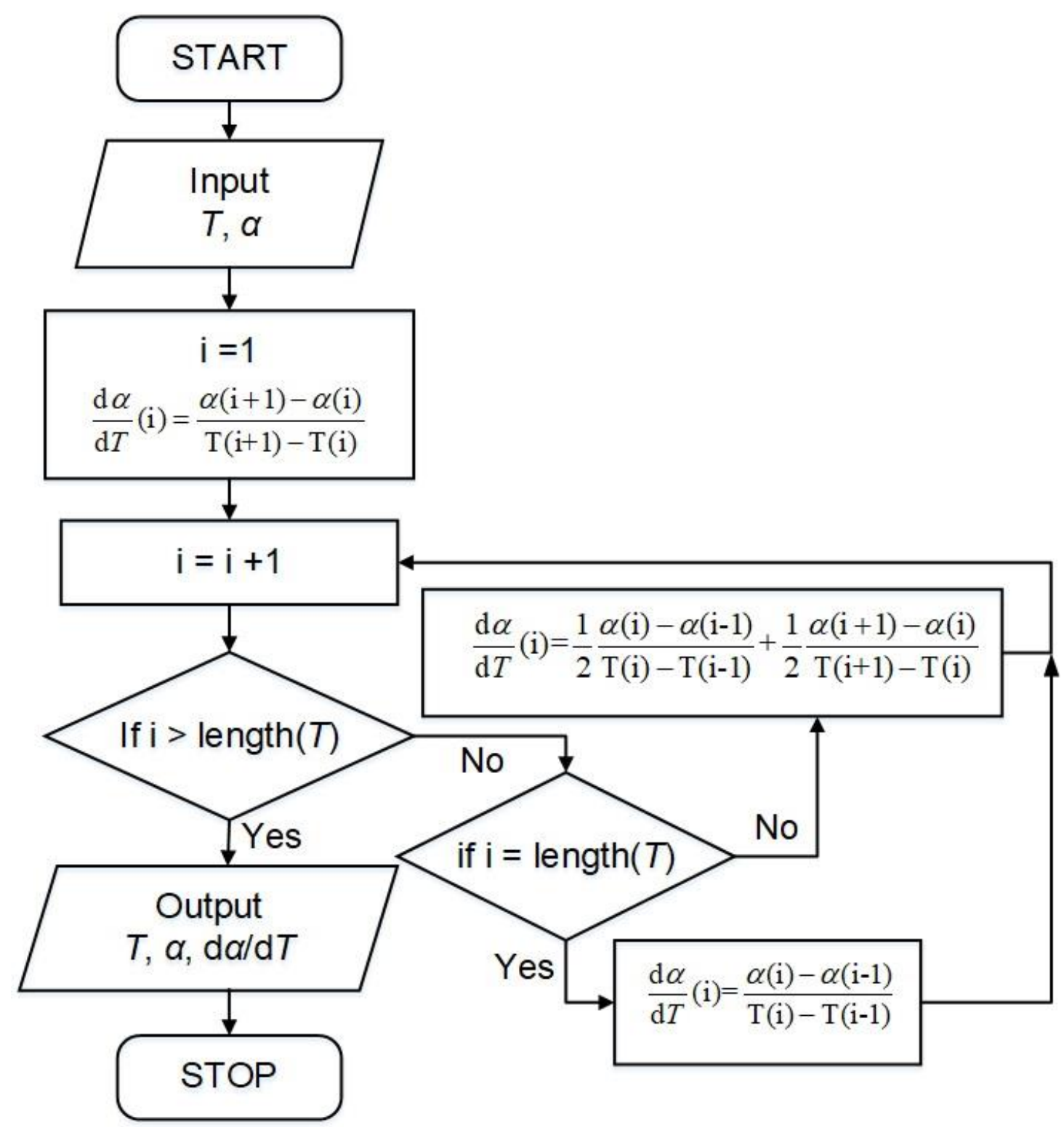

Figure 8. Flowchart of differentiating conversion data.

Figure 9 shows the $\alpha-T$ and $\mathrm{d} \alpha / \mathrm{d} T-T$ curves obtained according to the numerical method presented in Equation (3) of corn stalk pyrolysis at the heating rate of $2.5 \mathrm{~K}$ $\min ^{-1}$. 


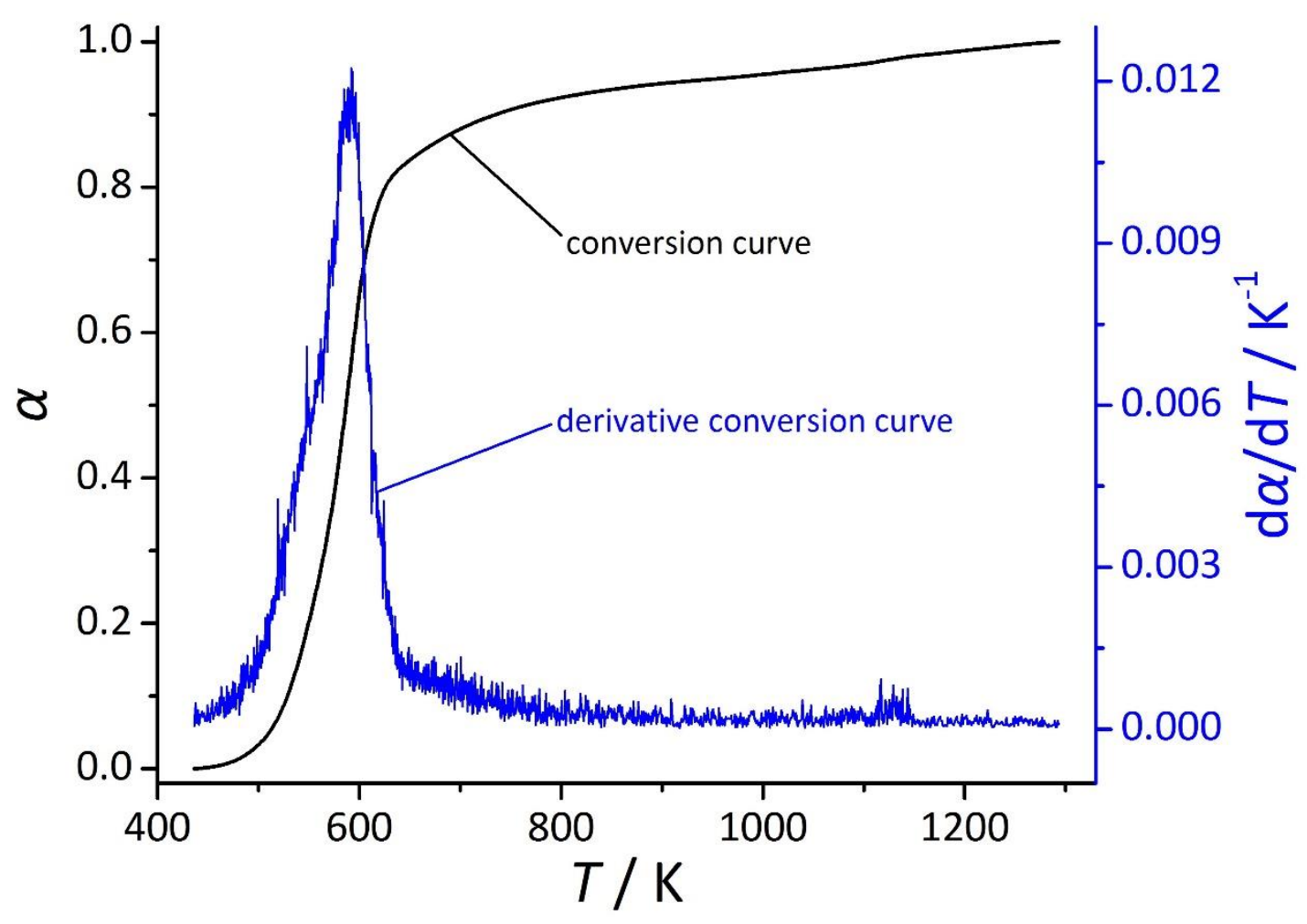

Figure 9. Conversion and derivative conversion curves (corn stalk pyrolysis at $2.5 \mathrm{~K}$ $\left.\min ^{-1}\right)$.

\subsection{Smoothing of derivative conversion}

From Figure 9, it can be seen that the derivative conversion curve has many fluctuations. It should be smoothed when the Friedman differential isoconversional method is used for further analysis [72].

There are many methods to smooth the noisy data, which can be divided in two types: parametric fitting methods and nonparametric fitting methods [73].

As for parametric fitting methods, some mathematical functions are used to fit the noisy data so that the resulting fitted curve then can be used for further analysis [74]. The common functions mentioned in published papers include the logistic function [75], Weibull distribution function [76, 77], and Fraser-Suzuki function [78-80]. According to Vyazovkin et al. [74], those mathematical functions could distort the kinetic parameters by inexact kinetic curve matching and by smoothing out real reaction 
features. The extreme right data points can affect the fitted values at the extreme left data points when the parametric fitting methods are used [81].

In the nonparametric fitting methods, a predetermined function form is not needed, and a smoothed data point is obtained based on the observation at that point and some specified neighboring points [82]. The common nonparametric fitting methods include the moving average, Savitzky-Golay, and locally weighted scatterplot smoothing (LOWESS) methods [83]. Chen et al. [84] used the moving average smoothing method to process the derivative thermogravimetric curves of pyrolysis of some woody biomass samples. Caballero and Conesa [85] suggested the Savitzky-Golay smoothing method to smooth noisy derivative thermogravimetric curves. Wu et al. [86] used the SavitzkyGolay smoothing method to smooth the derivative conversion curves of pyrolysis and combustion of tobacco waste. In the treatment of the moving average and SavitzkyGolay smoothing methods, the data points are all given equal weight. In fact, it is more reasonable giving more weight to points near the considering point and less weight to points further away. The LOWESS method can avoid the above problems. Yu et al. [38] used it to successfully smooth the derivative conversion data of pine sawdust biochar combustion. In the LOWESS procedure, at each data point a second polynomial is fitted to a subset of the noisy data using the weighted least squares regression. For the smoothing of the $i$ th data point, the flowchart of the LOWESS procedure is shown in Figure 10, where $x$ is a neighbor point within the fitting window associated to the current center point $x_{i}$, and $d_{i}$ is the half-width of the fitting window enclosing the observations for the local regression. 


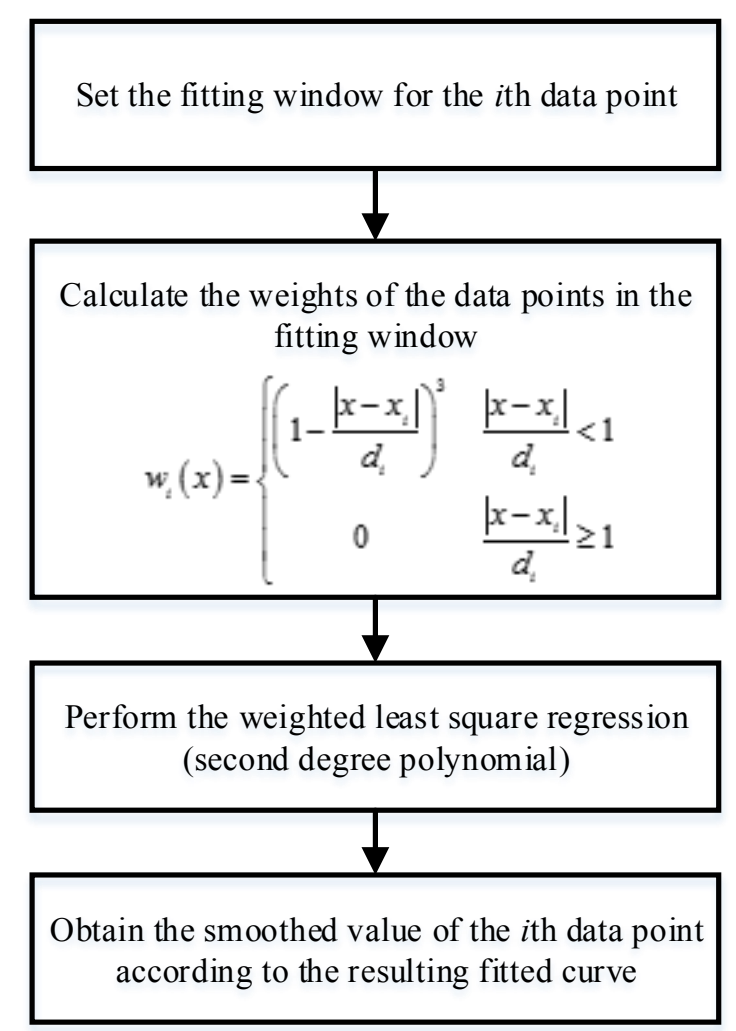

Figure 10. Flowchart of LOWESS procedure for smoothing.

The smoothing results with the LOWESS procedure depend on the size of the fitting window. In the literature, a smoothing parameter, $\mathrm{sp}$, is introduced to represent the size of the fitting window. Usually, the fraction of the data points used for smoothing at each data point is considered as sp. Figure 11 shows the smoothing results of derivative conversion curve of corn stalk pyrolysis at the heating rate of $2.5 \mathrm{~K} \mathrm{~min}^{-1}$ with $\mathrm{sp}=0.01$ and 0.1 . It can be observed that a smaller value for the smoothing parameter leads to less smoothing, while a larger value for the smoothing parameter results in more smoothing, perhaps even over smoothing. Therefore, there exists an optimal value for the smoothing parameter. 

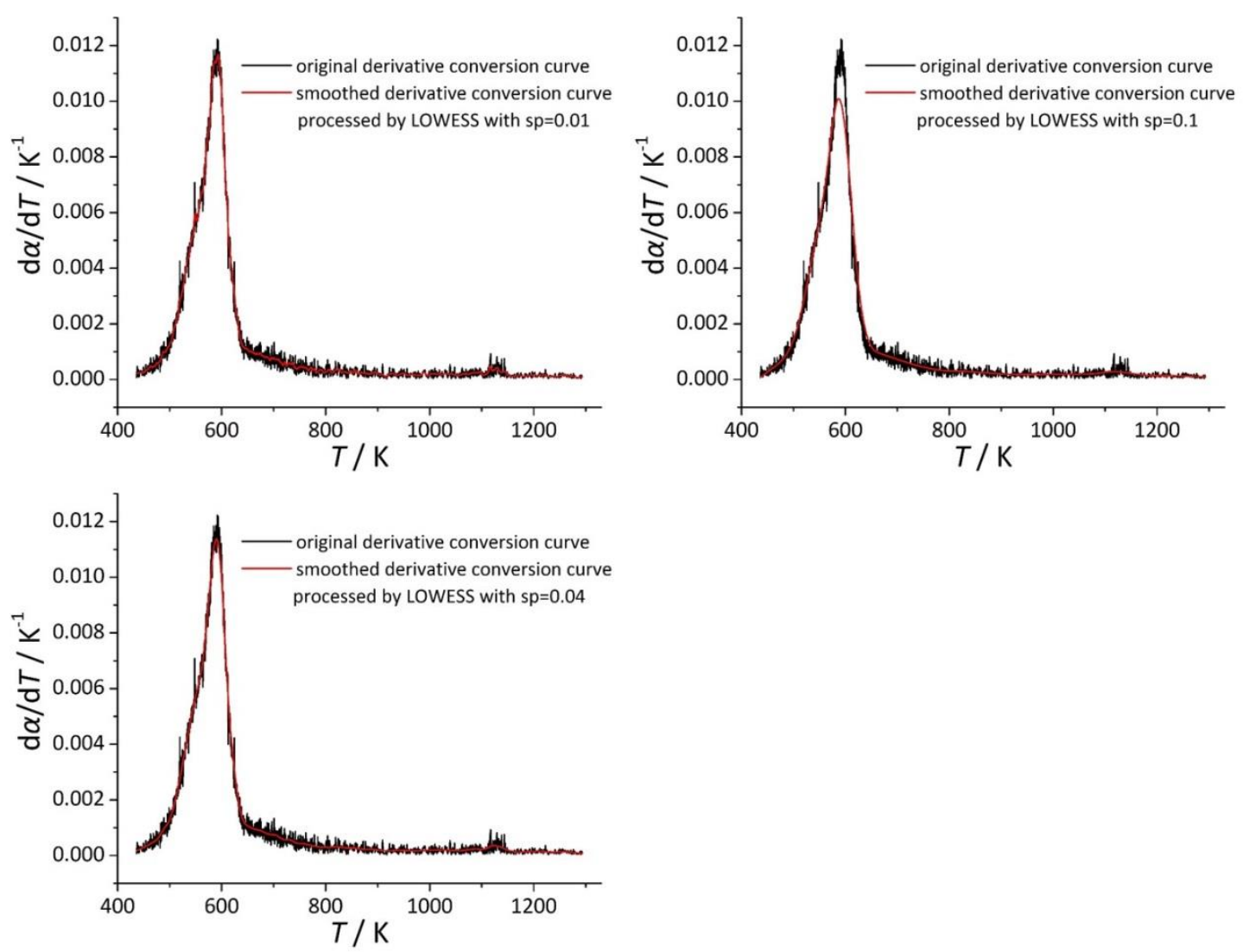

Figure 11. Smoothing of derivative conversion curve of corn stalk pyrolysis at $2.5 \mathrm{~K}$ $\min ^{-1}$ by LOWESS procedure with different smoothing parameter values.

There are some automatic methods to determine the optimal smoothing parameter [87]. The corrected Akaike information criteria (AICc) is one of the most effective methods [88]:

$$
\mathrm{AICc}=\log \left(\frac{\mathrm{RSS}}{n}\right)+\frac{\delta_{1} / \delta_{2}(n+v)}{\delta_{1}^{2} / \delta_{2}-2}
$$

where $n$ is the number of data points, RSS is the residual sum of squares between the noisy data and the smoothed data, $\delta_{1}=\operatorname{Trace}\left((I-L)^{T}(I-L)\right), \delta_{2}=\operatorname{Trace}\left((I-L)^{T}(I-L)\right)^{2}, v=$ $\operatorname{Trace}\left(L^{T} L\right)$. The matrix $I$ is the identity matrix and the smoothing matrix $L$ satisfies $y_{1}$ $=L y$, where $y$ is the vector of noisy data and $y_{1}$ is the corresponding vector of smoothed data. The optimal smoothing parameter yields the smallest AICc value.

The AICc values with a range of smoothing parameter values from 0.01 to 0.1 with an interval of 0.01 for smoothing of the derivative conversion curve of corn stalk 
pyrolysis at the heating rate of $2.5 \mathrm{~K} \mathrm{~min}^{-1}$ are shown in Figure 12. It can be obtained that the optimal smoothing parameter is 0.04 . The comparison between the original derivative conversion curve and the derivative conversion curve smoothed with the optimal smoothing parameter is also shown in Figure 11. It can be seen that smoothing with the optimal smoothing parameter is neither too little nor too much.

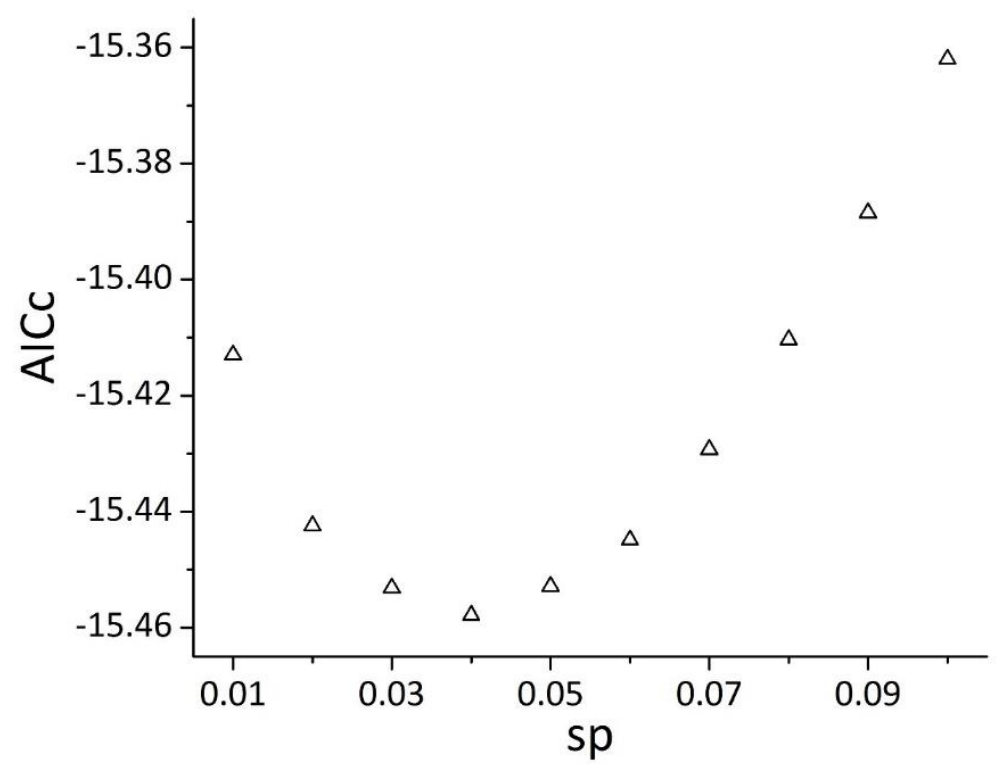

Figure 12. AICc values with various smoothing parameter values for smoothing of derivative conversion data of corn stalk pyrolysis at $2.5 \mathrm{~K} \mathrm{~min}^{-1}$ using LOWESS method.

\section{Isoconversional kinetic analysis}

\subsection{Estimation of temperature and derivative conversion at given conversions}

To apply the Friedman differential isoconversional method, the values of $T_{\alpha}$ and $(\mathrm{d} \alpha / \mathrm{d} T)_{\alpha}$ need to be estimated. Usually, these values are estimated from the $\alpha-T$ and smoothed $\mathrm{d} \alpha / \mathrm{d} T-T$ curves via an interpolation method. Interpolation methods can construct new data points within the range of a discrete set of known data points [89]. Common interpolation methods include near-neighbor interpolation, linear interpolation, and cubic spline interpolation methods [90]. The nearest neighbor 
interpolation selects the value of the nearest point, while the linear interpolation uses a linear polynomial to construct new data points [91]. The cubic spline interpolation takes a four-point moving window and fits a cubic polynomial between the four-point data set to construct new data points. It can offer true continuity between the data points. Therefore, it is usually used to determine $T_{\alpha}$ and $(\mathrm{d} \alpha / \mathrm{d} T)_{\alpha}$. Figure 13 shows the $T_{\alpha}$ and $(\mathrm{d} \alpha / \mathrm{d} T)_{\alpha}(\alpha=0.05: 0.05: 0.85)$ values obtained by the cubic spline interpolation of $\alpha-T$ and smoothed $\mathrm{d} \alpha / \mathrm{d} T-T$ curves of corn stalk pyrolysis at the heating rate of $2.5 \mathrm{~K} \mathrm{~min}^{-}$ 1 .

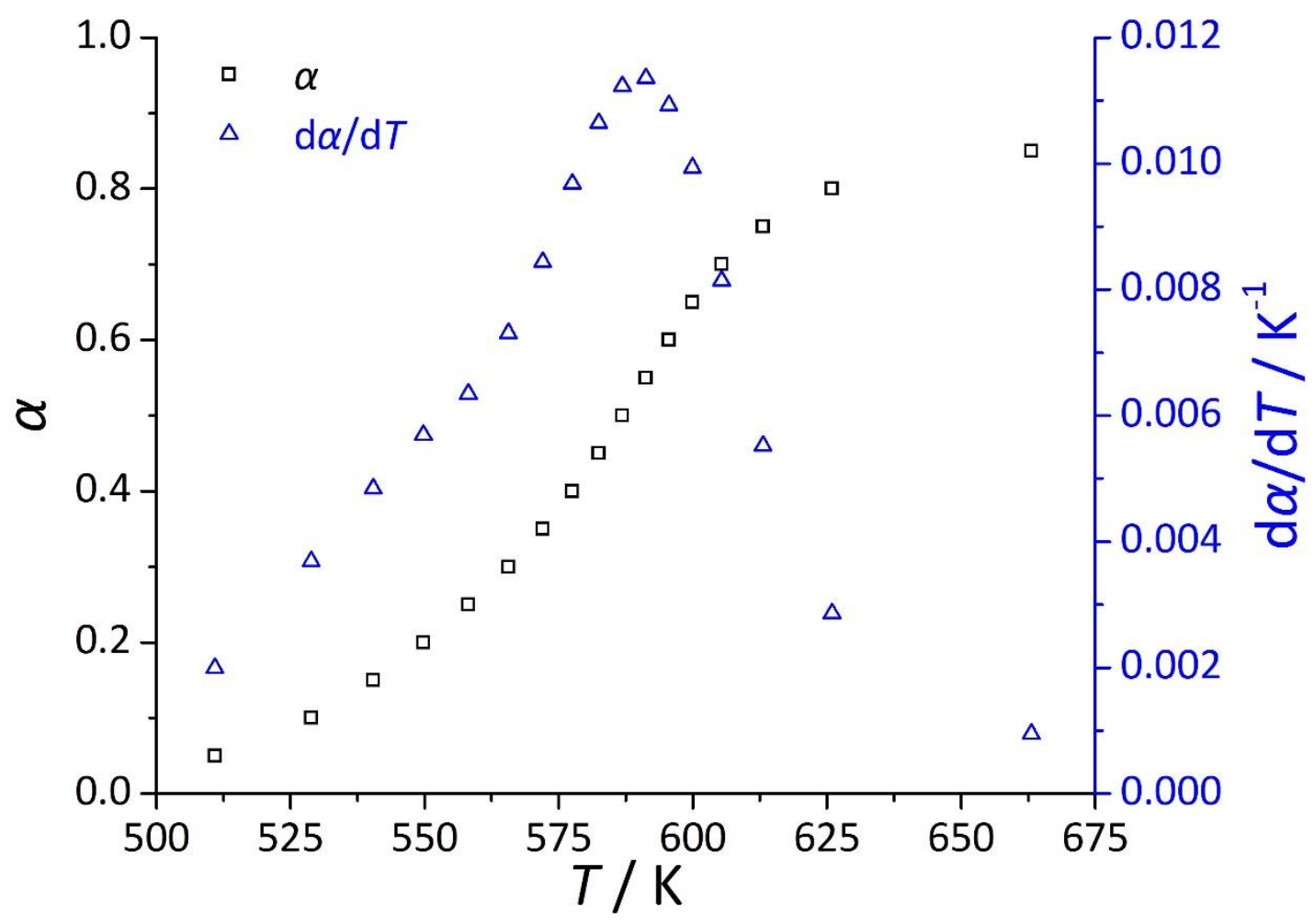

Figure 13. $T_{\alpha}$ and $(\mathrm{d} \alpha / \mathrm{d} T)_{\alpha}$ values at various $\alpha(0.05: 0.05: 0.85)$ obtained from cubic spline interpolation of $\alpha-T$ and smoothed $\mathrm{d} \alpha / \mathrm{d} T-T$ curves of corn stalk pyrolysis at

$$
2.5 \mathrm{~K} \mathrm{~min}^{-1} \text {. }
$$

\subsection{Isoconversional kinetic calculation}

The isoconversional kinetic methods are based on the following basic assumptions 
[92]: (1) the reaction rate at a certain conversion is only a function of temperature; (2) the conversion function and the kinetic parameters at a certain conversion are independent on the heating rate.

The rate of a thermally activated solid-state reaction under a linear heating program can be described by the following ordinary differential equation [93]:

$$
\beta \frac{\mathrm{d} \alpha}{\mathrm{d} T}=A e^{-E / R T} f(\alpha)
$$

where $A$ is the frequency factor, $E$ is the activation energy, $R$ is the universal gas constant and $f(\alpha)$ is differential form of the conversion function.

After taking a logarithm of both sides of Equation (5), one can obtain:

$$
\ln \left(\beta \frac{\mathrm{d} \alpha}{\mathrm{d} T}\right)=\ln [A f(\alpha)]-\frac{E}{R T}
$$

For a given conversion and a series of experiments at different heating rates, the above equation becomes:

$$
\ln \left(\left.\beta_{i} \frac{\mathrm{d} \alpha}{\mathrm{d} T}\right|_{\alpha, i}\right)=\ln \left[A_{\alpha} f(\alpha)\right]-\frac{E_{\alpha}}{R T_{\alpha, i}}
$$

where the subscript $i$ denotes the ordinal number of a nonisothermal experiment conducted at the heating rate $\beta_{i}$, and the subscript $a$ is the quantities evaluated at a specific degree of conversion $\alpha$. For a given $a, E_{a}$ and $\ln \left[A_{\alpha} f(\alpha)\right]$ can be obtained from the slope and intercept of the plot of $\ln \left[\beta_{i}(\mathrm{~d} \alpha / \mathrm{d} T)_{\alpha, i}\right]$ versus $\left(-1 / R T_{\alpha, i}\right)$, respectively.

Figure 14 shows the flowchart of the implementation of the Friedman isoconversional method. 


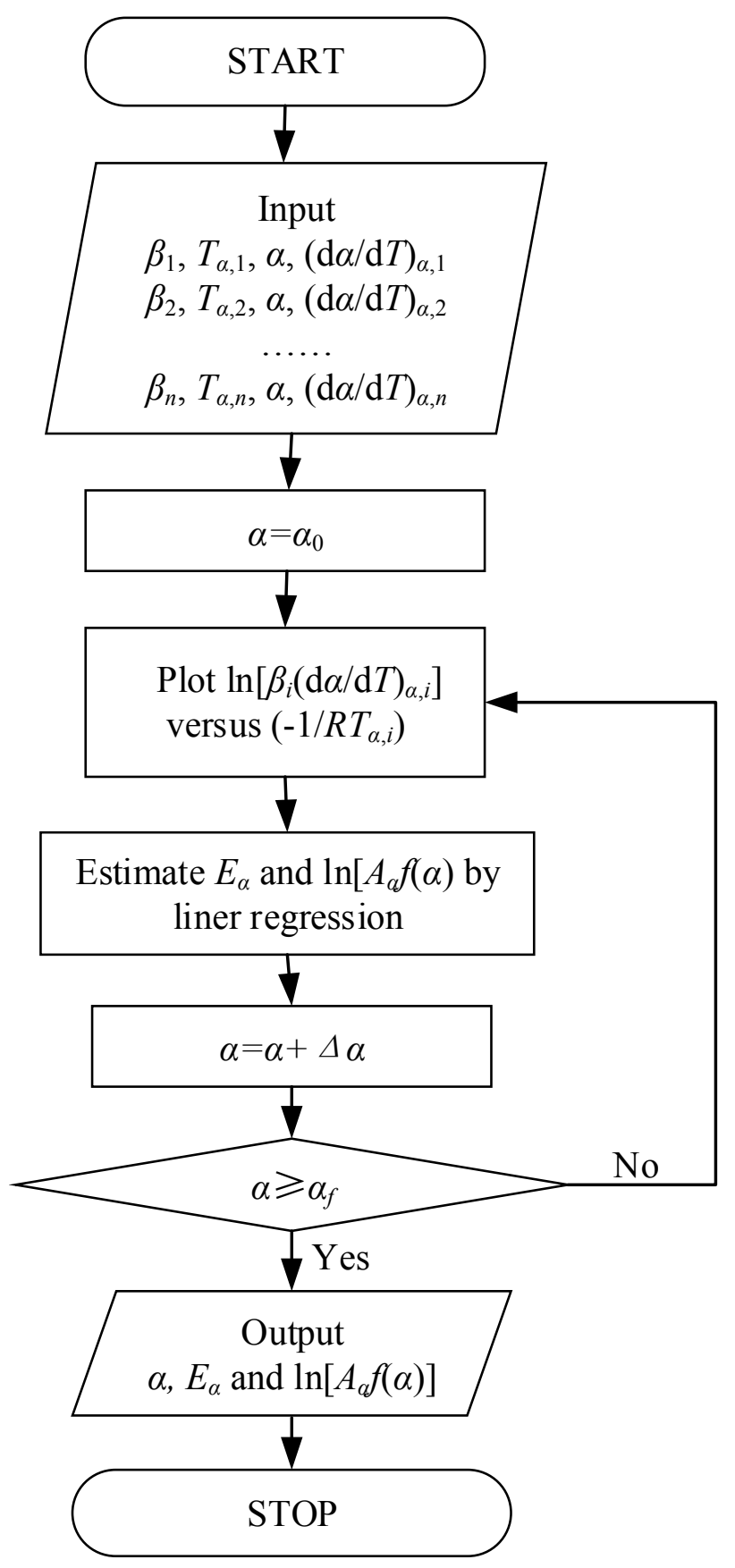

Figure 14. Flowchart of Friedman isoconversional method.

Figure 15 represents the smoothed $\beta(\mathrm{d} \alpha / \mathrm{d} T)$ versus $T$ curves for corn stalk pyrolysis at various heating rates of $2.5,5,10,20$ and $40 \mathrm{~K} \mathrm{~min}^{-1}$. It can be observed that (1) there is a peak and peak shoulder in the left side of the peak for each curve, (2) the peak value increases with the increasing of the heating rate, (3) the temperature at the peak increases with the increasing of the heating rate. Table 2 lists the information 
about the derivative conversion curve peaks at various heating rates for corn stalk pyrolysis.

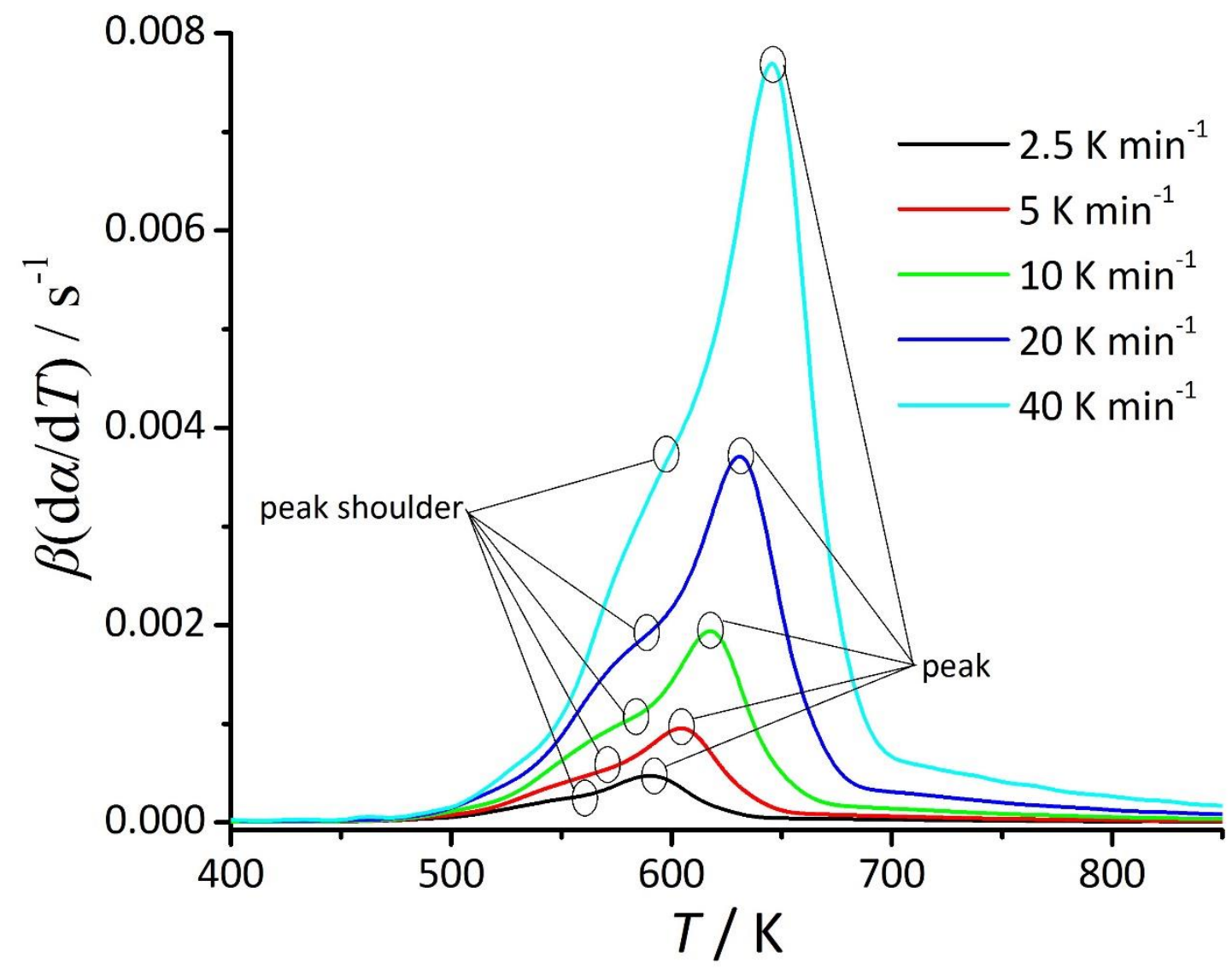

Figure 15. Smoothed derivative conversion curves at various heating rates for corn stalk pyrolysis

Table 2. Characterization of peak of derivative conversion curves at various heating rates for corn stalk pyrolysis

\begin{tabular}{ccc}
\hline$\beta / \mathrm{K} \mathrm{min}^{-1}$ & $T_{p} / \mathrm{K}$ & $\left.\beta \frac{d \alpha}{d T}\right|_{T_{p}} / \mathrm{s}^{-1}$ \\
\hline 2.5 & 592.0 & $4.717 \times 10^{-4}$ \\
5 & 605.1 & $9.545 \times 10^{-4}$ \\
10 & 617.4 & $1.940 \times 10^{-3}$ \\
20 & 631.2 & $3.710 \times 10^{-3}$ \\
40 & 645.8 & $7.693 \times 10^{-3}$ \\
\hline
\end{tabular}


Based on the conversion and smoothed derivative conversion curves, the corresponding values of $T_{\alpha}$ and $(\mathrm{d} \alpha / \mathrm{d} T)_{\alpha}$ values at various conversion values can be obtained by means of the cubic spline interpolation method mentioned above. Then, a tool called the Friedman isoconversional plots [94] can be used, where the $\ln \left[\beta_{i}(\mathrm{~d} \alpha / \mathrm{d} T)_{\alpha, i}\right]$ versus $-1 / R T_{\alpha, i}$ data at all heating rates and their corresponding linear regression lines for various conversions are presented. The coefficients of determination $\left(\mathrm{R}^{2}\right)$ of linear regressions for various conversions can be given, which is a measure of the goodness-of-fit [95].

Figure 16 shows the Friedman isoconversional plots for corn stalk pyrolysis. Table 3 lists the correlation coefficients of the linear regressions presented in Figure 16. In Figure 16, $-1000 / R T_{\alpha, i}$ (not $-1 / R T_{\alpha, i}$ ) is used, because the resulting $E_{a}$ can be directly expressed in $\mathrm{kJ} \mathrm{mol}^{-1}\left(\mathrm{~kJ} \mathrm{~mol}^{-1}\right.$ is the common unit for activation energy). From the results included in Figure 16 and Table 3, the perfect linear relationship for most conversions was obtained, except for the conversion of 0.85 . The $\mathrm{R}^{2}$ value at the conversion of 0.85 is less than 0.9 . Usually, the differences among the experimental data at different heating rates at high conversions (e.g. $a \geq 0.85$ ) are very small, the results obtained by the Friedman isoconversional method contain large errors [72]. 


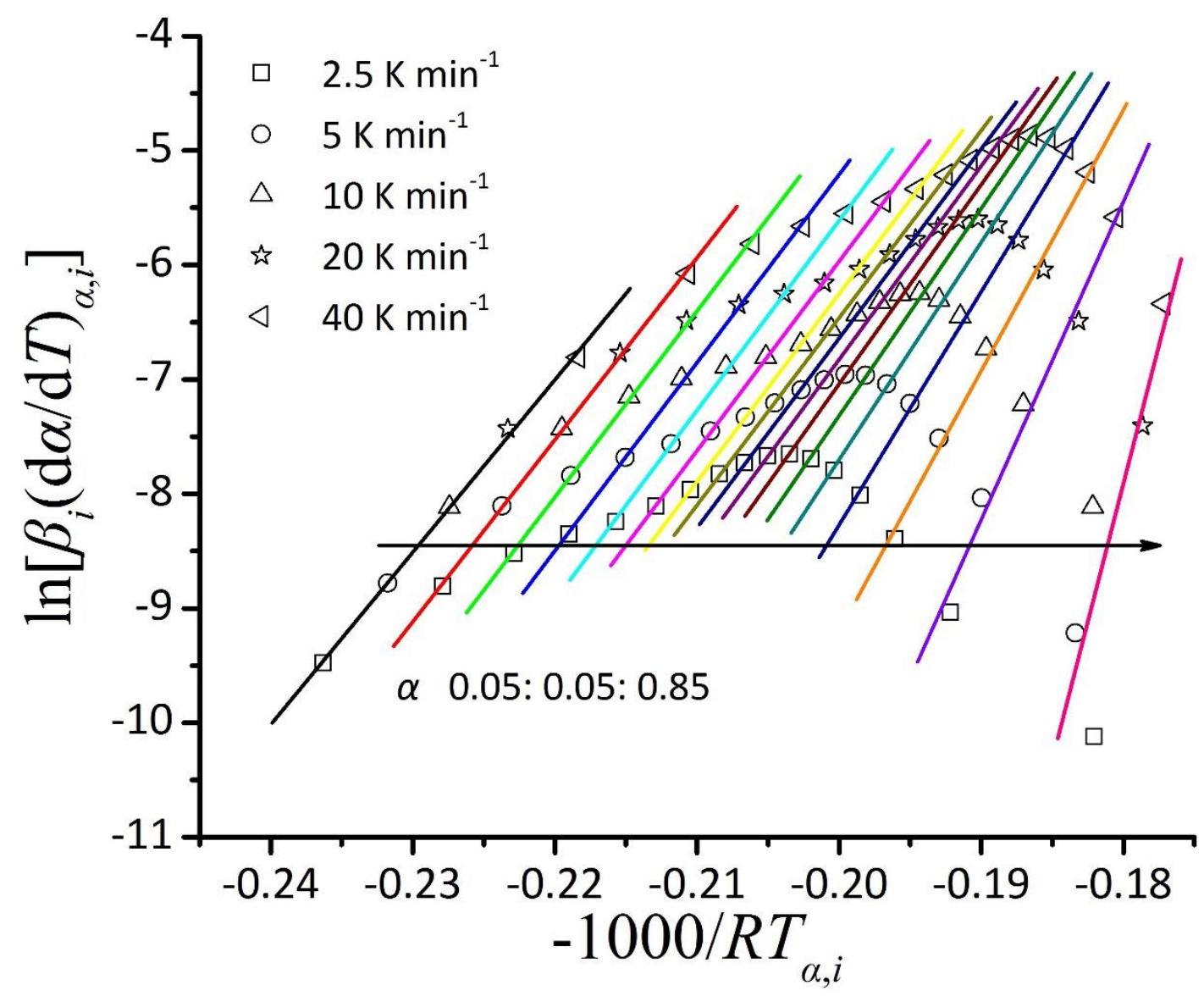

Figure 16. Friedman isoconversional plots at selected conversion values for corn stalk pyrolysis.

Table 3. Correlation coefficients of linear regressions presented in Figure 16

\begin{tabular}{cccccc}
\hline$\alpha$ & $\mathrm{R}^{2}$ & $\alpha$ & $\mathrm{R}^{2}$ & $\alpha$ & $\mathrm{R}^{2}$ \\
\hline 0.05 & 0.9996 & 0.35 & 0.9999 & 0.65 & 0.9954 \\
0.1 & 1.0000 & 0.4 & 0.9999 & 0.7 & 0.9933 \\
0.15 & 1.0000 & 0.45 & 0.9997 & 0.75 & 0.9912 \\
0.2 & 0.9995 & 0.5 & 0.9992 & 0.8 & 0.9875 \\
0.25 & 0.9992 & 0.55 & 0.9984 & 0.85 & 0.8998 \\
0.3 & 0.9997 & 0.6 & 0.9971 & & \\
\hline
\end{tabular}

By means of the Friedman isoconversional calculations, the values of $E_{\alpha}$ and $\ln \left[A_{\alpha} f(\alpha)\right]$ for corn stalk pyrolysis can be obtained, as shown in Figure 17. 


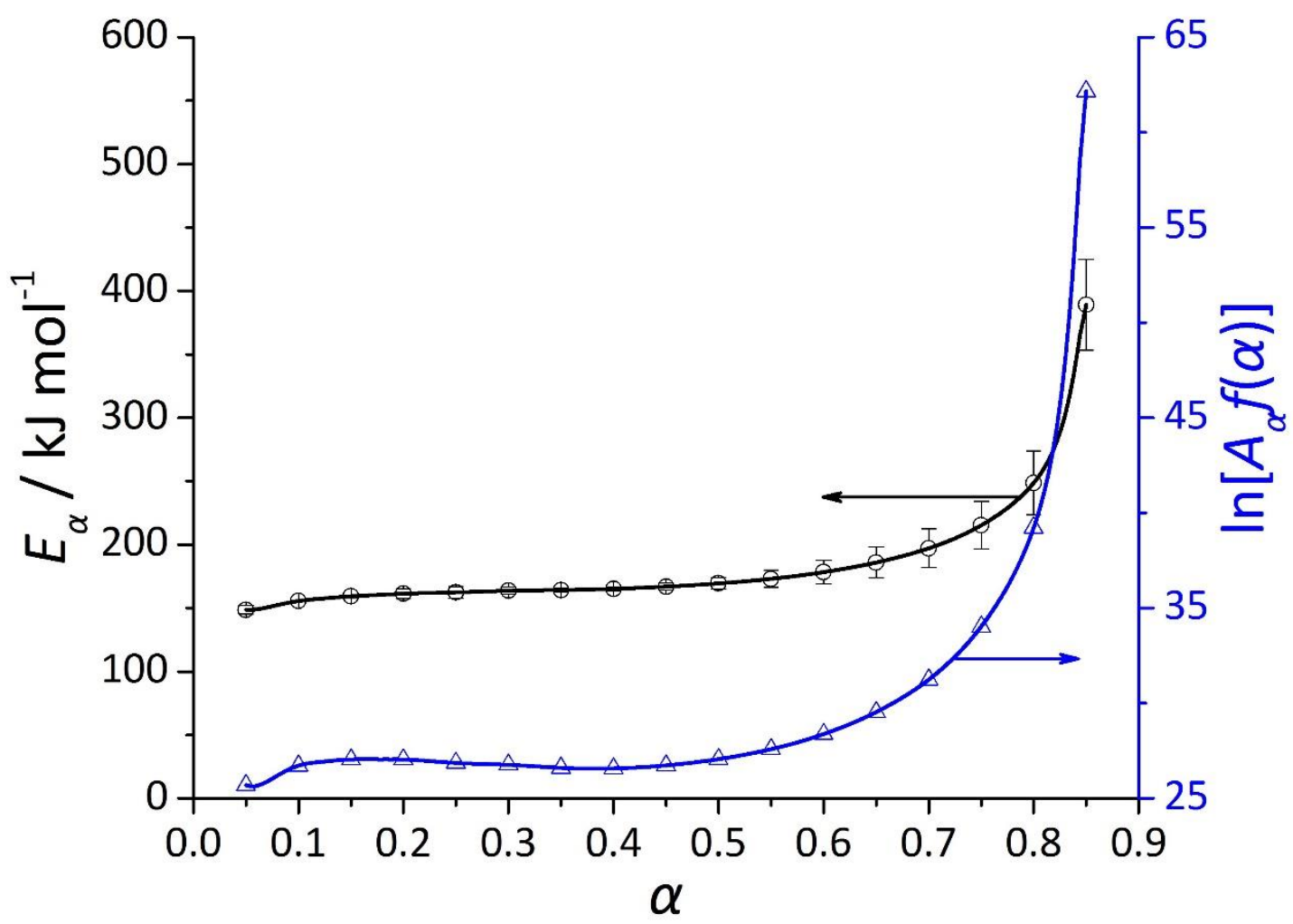

Figure 17. $E_{\alpha}$ and $\ln \left[A_{\alpha} f(\alpha)\right]$ as a function of conversion for corn stalk pyrolysis. Error bars represent confidence intervals.

From Figure 17, it can be observed that $E_{\alpha}$ depends on $\alpha$ : (1) $E_{\alpha}$ gradually increases from 148 to $186 \mathrm{~kJ} \mathrm{~mol}^{-1}$ when $\alpha$ increases from 0.05 to 0.65 ; (2) $E_{\alpha}$ sharply increase from 186 to $473 \mathrm{~kJ} \mathrm{~mol}^{-1}$ in the $\alpha$ range between 0.65 and 0.85 . The similar trend of the variation of $E_{\alpha}$ with $\alpha$ can be found in the pyrolysis of the acid hydrolysis residue of miscanthus [96]. The activation energies ranged from 200 to $376 \mathrm{~kJ} \mathrm{~mol}^{-1}$ increasing with increasing conversion $(0.15 \sim 0.85)$. Other similar results were produced in the pyrolysis of tobacco waste [86], eucalyptus wood [47], polyether ether ketone and its carbon fiber composites [97], rice husk [98], rape straw [99], and microalgae [100].

Corn stalk is a typical lignocellulosic biomass, which contains cellulose, hemicellulose, and lignin. The pyrolysis of corn stalk involves multistep processes of those components. In the literature [101, 102], the researchers usually gave a mean value of the resultant activation energies obtained from isoconversional methods. In fact, the mean activation energy value is meaningless. According to Vyazovkin [103], 
the effective activation energy of lignocellulosic biomass has a meaning of a collective parameter linked to the activation energies of individual decomposition processes of those biopolymer components. And for the pyrolysis of cellulose, hemicellulose or lignin involves a distribution of activation energies [70]. Therefore, the effective activation energies could significantly vary with conversion. Wu et al. [86] put the curves of $E_{\alpha}$ vs. $\alpha, \alpha$ vs. $T$ and $\mathrm{d} \alpha / \mathrm{d} T$ vs. $T$ together and linked them with some lines, which provided an easy way to better understand the relationship between the decomposition reactions of lignocellulosic components and the resultant effective activation energies of lignocellulosic biomass pyrolysis. Marion et al. [47] discussed the relationship between the $E_{\alpha}$ dependency and the decomposition reactions of lignocellulosic components.

\section{Verification}

The use of most isoconversional methods (e.g. FWO, KAS and Vyazovkin methods) can lead to the estimation of only activation energies. So most published papers related on isoconversional kinetic analysis of solid state reactions only focused on the determination of the activation energies. It is impossible to reproduce the kinetic data with only activation energies. Therefore, the comparison between the experimental data and the predicted results from isoconversional kinetic analysis can't be performed. Whether the resulting activation energies fitted the experimental data well or not is unknown.

The use of the Friedman isoconversional method can give the values of $E_{\alpha}$ and $\ln \left[A_{\alpha} f(\alpha)\right]$, which makes it possible to reconstruct the kinetic process.

According to Equation (5), the following equation can be obtained:

$$
\frac{\mathrm{d} T}{\mathrm{~d} \alpha}=\beta e^{E_{\alpha} / R T-\ln \left[A_{\alpha} f(\alpha)\right]}
$$

Based on the $E_{\alpha}$ and $\ln \left[A_{\alpha} f(\alpha)\right]$ values at various $\alpha$ obtained from the Friedman isoconversional method, the above ordinary differential equation (8) can be numerically solved by means of the classical fourth-order Runge-Kutta method and then the temperature values at a certain $\beta$ and various $\alpha$ values. 
Figure 18 shows the comparison between the experimental data and the kinetic simulation based on the $E_{\alpha}$ and $\ln \left[A_{\alpha} f(\alpha)\right]$ values for corn stalk pyrolysis. It can be observed that the kinetic simulation fitted the experimental data very well, which indicated that the obtained kinetic parameters were effective.

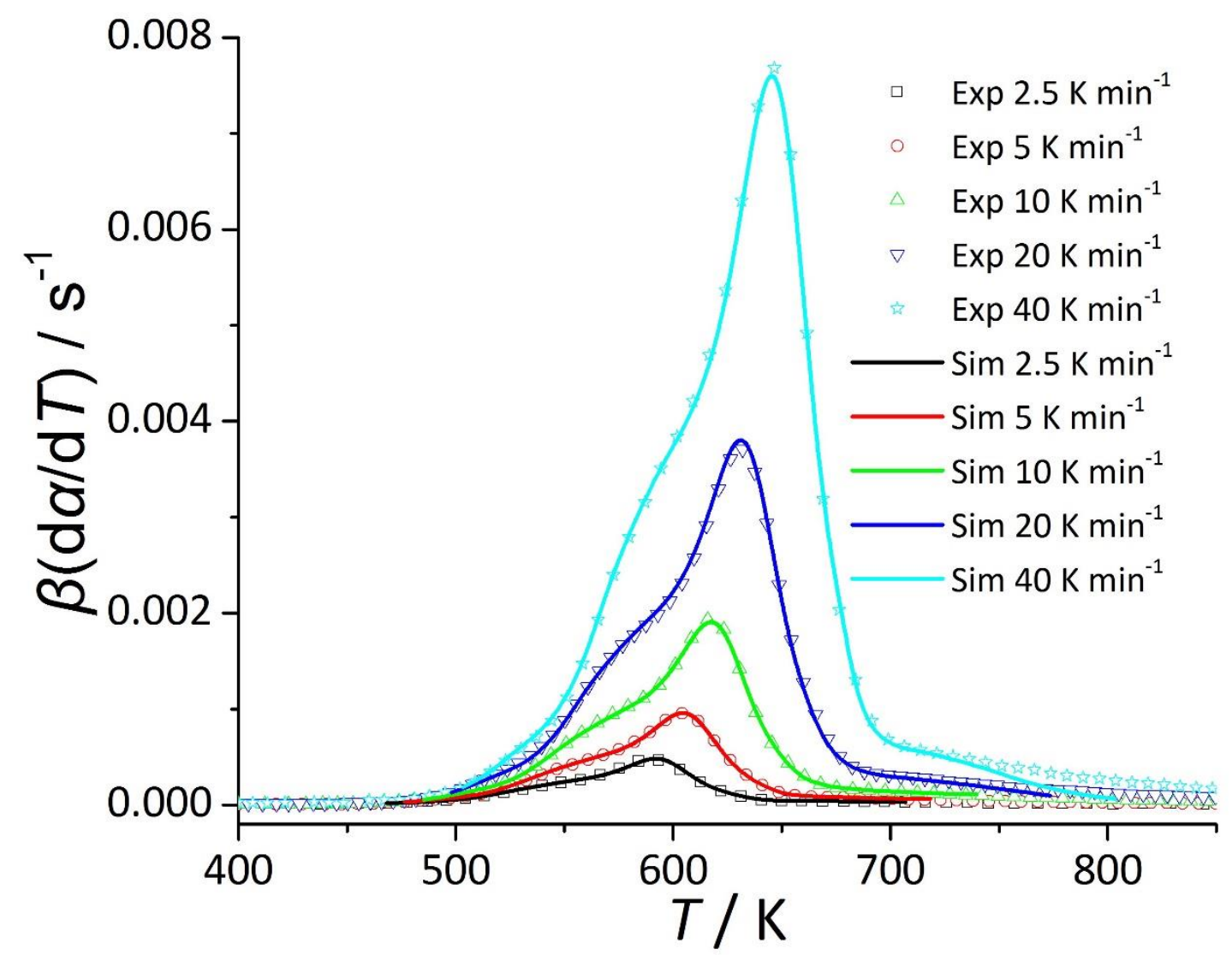

Figure 18. Comparison between experimental data and kinetic simulation based on $E_{\alpha}$ and $\ln \left[A_{\alpha} f(\alpha)\right]$ for corn stalk pyrolysis at $2.5,5,10,20$ and $40 \mathrm{~K} \mathrm{~min}^{-1}$ (in the figure, Exp represents the experimental data, Sim represents the kinetic simulation based on the isoconversional kinetic analysis results).

\section{Conclusions}

Kinetic information (in particular effective activation energy) is essential necessary for the design and optimization of lignocellulosic biomass pyrolysis processes. TGA can provide an effective way to obtain experimental kinetic data. From experimental TGA data to the effective activation energies of lignocellulosic biomass pyrolysis, there are some processes involved in the Friedman isoconversional kinetic 
analysis: the removal of "error" data points, the removal of dehydration stage, the transformation of TGA data to $\alpha-T$ data, the differentiation of $\alpha-T$ data to get $\mathrm{d} \alpha / \mathrm{d} T$ $-T$ data, the smoothing of noisy $\mathrm{d} \alpha / \mathrm{d} T-T$ data, the interpolation of $\alpha-T$ and smoothed $\mathrm{d} \alpha / \mathrm{d} T-T$ data to get $T_{\alpha}$ and $(\mathrm{d} \alpha / \mathrm{d} T)_{\alpha}$ data at various $\alpha$, the Friedman isoconversional calculations for the determination of $E_{\alpha}$ and $\ln \left[A_{\alpha} f(\alpha)\right]$ at various $\alpha$, the reconstruction of kinetic process according to the resulting $E_{\alpha}$ and $\ln \left[A_{\alpha} f(\alpha)\right]$ and the comparison between the experimental data and the calculated data based on the kinetic parameters from isoconversional kinetic analysis.

A case study of corn stalk pyrolysis has been also presented in this paper. The results have shown that $E_{\alpha}$ gradually increases from 148 to $186 \mathrm{~kJ} \mathrm{~mol}^{-1}$ when $\alpha$ increases from 0.05 to 0.65 and $E_{\alpha}$ sharply increases from 186 to $473 \mathrm{~kJ} \mathrm{~mol}^{-1}$ in the $\alpha$ range between 0.65 and 0.85 . The variation of $E_{\alpha}$ with $\alpha$ is attributed to collective link of the different pyrolysis kinetic behaviors of lignocellulosic components (e.g., cellulose, hemicellulose and lignin) contained in corn stalk. Similar results can be found in the pyrolysis of other lignocellulosic biomass feedstocks.

It is worth noting that the general procedure presented in this paper can be also used for processing TGA data of the thermochemical conversion (pyrolysis, combustion or gasification) of other types of lignocellulosic biomass materials or solid fuels such as coal, polymer, oil shale, and waste plastic.

\section{Acknowledgements}

Junmeng gratefully acknowledge the financial support from Shanghai Jiao Tong University (IPP 15137). Xi Yu and Anthony V. Bridgwater gratefully acknowledge the research grant from EPSRC (EP/M01343X/1).

\section{References}

[1] Esen M, Yuksel T. Experimental evaluation of using various renewable energy sources for heating a greenhouse. Energy \& Buildings. 2013;65:340-51.

[2] Ozturk M, Saba N, Altay V, Iqbal R, Hakeem KR, Jawaid M, et al. Biomass and bioenergy: An overview of the development potential in Turkey and Malaysia. 
Renewable and Sustainable Energy Reviews. 2017;79:1285-302.

[3] Di Blasi C. Modeling chemical and physical processes of wood and biomass pyrolysis. Progress in Energy and Combustion Science. 2008;34:47-90.

[4] Bridgwater AV, Peacocke GVC. Fast pyrolysis processes for biomass. Renewable and Sustainable Energy Reviews. 2000;4:1-73.

[5] Neves D, Thunman H, Matos A, Tarelho L, Gómez-Barea A. Characterization and prediction of biomass pyrolysis products. Progress in Energy and Combustion Science. 2011;37:611-30.

[6] Akhtar J, Saidina Amin N. A review on operating parameters for optimum liquid oil yield in biomass pyrolysis. Renewable and Sustainable Energy Reviews. 2012;16:5101-9.

[7] Kan T, Strezov V, Evans TJ. Lignocellulosic biomass pyrolysis: A review of product properties and effects of pyrolysis parameters. Renewable and Sustainable Energy Reviews. 2016;57:1126-40.

[8] Collard F-X, Blin J. A review on pyrolysis of biomass constituents: Mechanisms and composition of the products obtained from the conversion of cellulose, hemicelluloses and lignin. Renewable and Sustainable Energy Reviews. 2014;38:594608.

[9] Bridgwater AV, Meier D, Radlein D. An overview of fast pyrolysis of biomass. Organic Geochemistry. 1999;30:1479-93.

[10] Bridgwater AV. Principles and practice of biomass fast pyrolysis processes for liquids. Journal of Analytical and Applied Pyrolysis. 1999;51:3-22.

[11] Garcia-Nunez JA, Pelaez-Samaniego MR, Garcia-Perez ME, Fonts I, Abrego J, Westerhof RJM, et al. Historical developments of pyrolysis reactors: A review. Energy \& Fuels. 2017;31:5751-75.

[12] Mohan D, Pittman CU, Steele PH. Pyrolysis of Wood/Biomass for Bio-oil: A Critical Review. Energy \& Fuels. 2006;20:848-89.

[13] Yu Y, Yang Y, Cheng Z, Blanco PH, Liu R, Bridgwater AV, et al. Pyrolysis of rice husk and corn stalk in auger reactor. 1. characterization of char and gas at various 
temperatures. Energy \& Fuels. 2016;30:10568-74.

[14] Babler MU, Phounglamcheik A, Amovic M, Ljunggren R, Engvall K. Modeling and pilot plant runs of slow biomass pyrolysis in a rotary kiln. Applied Energy. 2017. [15] Li Z, Li N, Yi W, Fu P, Li Y, Bai X. Design and operation of a down-tube reactor demonstration plant for biomass fast pyrolysis. Fuel Processing Technology. 2017;161:182-92.

[16] Cai W, Liu R. Performance of a commercial-scale biomass fast pyrolysis plant for bio-oil production. Fuel. 2016;182:677-86.

[17] Wang S, Dai G, Yang H, Luo Z. Lignocellulosic biomass pyrolysis mechanism: A state-of-the-art review. Progress in Energy and Combustion Science. 2017;62:33-86.

[18] Dhyani V, Bhaskar T. A comprehensive review on the pyrolysis of lignocellulosic biomass. Renewable Energy. 2017.

[19] Ciuta S, Patuzzi F, Baratieri M, Castaldi MJ. Biomass energy behavior study during pyrolysis process by intraparticle gas sampling. Journal of Analytical \& Applied Pyrolysis. 2014;108:316-22.

[20] Xiong Q, Yang Y, Xu F, Pan Y, Zhang J, Hong K, et al. Overview of computational fluid dynamics simulation of reactor-scale biomass pyrolysis. ACS Sustainable Chemistry \& Engineering. 2017;5:2783-98.

[21] Wang Y, Yan L. CFD studies on biomass thermochemical conversion. International Journal of Molecular Sciences. 2008;9:1108-30.

[22] Van de Velden M, Baeyens J, Brems A, Janssens B, Dewil R. Fundamentals, kinetics and endothermicity of the biomass pyrolysis reaction. Renewable Energy. 2010;35:232-42.

[23] Bach Q-V, Chen W-H. Pyrolysis characteristics and kinetics of microalgae via thermogravimetric analysis (TGA): A state-of-the-art review. Bioresource Technology. 2017:doi: 10.1016/j.biortech.2017.06.087.

[24] White JE, Catallo WJ, Legendre BL. Biomass pyrolysis kinetics: A comparative critical review with relevant agricultural residue case studies. Journal of Analytical and Applied Pyrolysis. 2011;91:1-33. 
[25] Saddawi A, Jones JM, Williams A, Wójtowicz MA. Kinetics of the thermal decomposition of biomass. Energy and Fuels. 2010;24:1274-82.

[26] Jain AA, Mehra A, Ranade VV. Processing of TGA data: Analysis of isoconversional and model fitting methods. Fuel. 2016;165:490-8.

[27] Vyazovkin S, Wight CA. Model-free and model-fitting approaches to kinetic analysis of isothermal and nonisothermal data. Thermochimica Acta. 1999;340341:53-68.

[28] Burnham AK, Dinh LN. A comparison of isoconversional and model-fitting approaches to kinetic parameter estimation and application predictions. Journal of Thermal Analysis and Calorimetry. 2007;89:479-90.

[29] Sánchez-Jiménez PE, Pérez-Maqueda LA, Perejón A, Criado JM. Limitations of model-fitting methods for kinetic analysis: Polystyrene thermal degradation. Resources, Conservation and Recycling. 2013;74:75-81.

[30] Friedman HL. Kinetics of thermal degradation of char-forming plastics from thermogravimetry. Application to a phenolic plastic. Journal of Polymer Science Part C: Polymer Symposia. 1964;6:183-95.

[31] Ozawa T. A new method of analyzing thermogravimetric data. Bulletin of the Chemical Society of Japan. 1965;38:1881-6.

[32] Flynn JH, Wall LA. General treatment of the thermogravimetry of polymers. Journal of Research of the National Bureau of Standards - A Physics and Chemistry. 1966;70A:487-523.

[33] Kissinger HE. Variation of peak temperature with heating rate in differential thermal analysis. Journal of Research of the National Bureau of Standards. 1956;57:217-21.

[34] Vyazovkin S, Dollimore D. Linear and Nonlinear Procedures in Isoconversional Computations of the Activation Energy of Nonisothermal Reactions in Solids. Journal of Chemical Information and Computer Sciences. 1996;36:42-5.

[35] Vyazovkin S. Modification of the integral isoconversional method to account for variation in the activation energy. Journal of Computational Chemistry. 2001;22:178- 
83.

[36] Cai J, Chen S. A new iterative linear integral isoconversional method for the determination of the activation energy varying with the conversion degree. Journal of Computational Chemistry. 2009;30:1986-91.

[37] Huidobro JA, Iglesias I, Alfonso BF, Espina A, Trobajo C, Garcia JR. Reducing the effects of noise in the calcualtion of activation energy by the Friedman method. Chemometrics and Intelligent Laboratory Systems. 2016;151:146-52.

[38] Yu Y, Fu X, Yu L, Liu R, Cai J. Combustion kinetics of pine sawdust biochar: Data smoothing and isoconversional kinetic analysis. Journal of Thermal Analysis and Calorimetry. 2016;124:1641-9.

[39] Cai JM, Bi LS. Kinetic analysis of wheat straw pyrolysis using isoconversional methods. Journal of Thermal Analysis and Calorimetry. 2009;98:325-30.

[40] Mehmood MA, Ye G, Luo H, Liu C, Malik S, Afzal I, et al. Pyrolysis and kinetic analyses of Camel grass (Cymbopogon schoenanthus) for bioenergy. Bioresource Technology. 2017;228:18-24.

[41] Rueda-Ordóñez YJ, Tannous K. Isoconversional kinetic study of the thermal decomposition of sugarcane straw for thermal conversion processes. Bioresource Technology. 2015;196:136-44.

[42] Mishra G, Bhaskar T. Non isothermal model free kinetics for pyrolysis of rice straw. Bioresource Technology. 2014;169:614-21.

[43] Mothé CG, De Miranda IC. Study of kinetic parameters of thermal decomposition of bagasse and sugarcane straw using Friedman and Ozawa-Flynn-Wall isoconversional methods. Journal of Thermal Analysis and Calorimetry. 2013;113:497-505.

[44] Biagini E, Guerrini L, Nicolella C. Development of a variable activation energy model for biomass devolatilization. Energy and Fuels. 2009;23:3300-6.

[45] Wu W, Mei Y, Zhang L, Liu R, Cai J. Effective activation energies of lignocellulosic biomass pyrolysis. Energy \& Fuels. 2014;28:3916-23.

[46] Caballero JA, Conesa JA. Mathematical considerations for nonisothermal kinetics in thermal decomposition. Journal of Analytical and Applied Pyrolysis. 2005;73:85- 
100.

[47] Carrier M, Auret L, Bridgwater A, Knoetze JH. Using apparent activation energy as a reactivity criterion for biomass pyrolysis. Energy \& Fuels. 2016;30:7834-41.

[48] Gabbott P. Principles and Applications of Thermal Analysis: Wiley; 2008.

[49] Vyazovkin S, Chrissafis K, Di Lorenzo ML, Koga N, Pijolat M, Roduit B, et al. ICTAC Kinetics Committee recommendations for collecting experimental thermal analysis data for kinetic computations. Thermochimica Acta. 2014;590:1-23.

[50] Cai J, He Y, Yu X, Banks SW, Yang Y, Zhang X, et al. Review of physicochemical properties and analytical characterization of lignocellulosic biomass. Renewable and Sustainable Energy Reviews. 2017;76:309-22.

[51] Brown ME. Introduction to Thermal Analysis: Techniques and Applications. 2 ed: Springer Netherlands; 2011.

[52] ASTM E2105-00. Standard Practice for General Techniques of Thermogravimetric Analysis (TGA) Coupled With Infrared Analysis (TGA/IR). West Conshohocken, PA: ASTM International; 2016.

[53] Singh S, Wu C, Williams PT. Pyrolysis of waste materials using TGA-MS and TGA-FTIR as complementary characterisation techniques. Journal of Analytical and Applied Pyrolysis. 2012;94:99-107.

[54] Nsaful F, Collard F-X, Carrier M, Görgens JF, Knoetze JH. Lignocellulose pyrolysis with condensable volatiles quantification by thermogravimetric analysisThermal desorption/gas chromatography-mass spectrometry method. Journal of Analytical and Applied Pyrolysis. 2015;116:86-95.

[55] Ball DJ, Norwood DL, Nagao LM, Stults CLM. Leachables and Extractables Handbook: Safety Evaluation, Qualification, and Best Practices Applied to Inhalation Drug Products: Wiley; 2012.

[56] Wang S, Luo Z, Media CSP. Pyrolysis of Biomass: De Gruyter; 2017.

[57] Jankovic BZ, Jankovic MM. Pyrolysis of pine and beech wood samples under isothermal experimental conditions. The determination of kinetic triplets. Cellulose Chemistry \& Technology. 2013;47:681-97. 
[58] Wu W, Cai J, Liu R. Isoconversional Kinetic Analysis of Distributed Activation Energy Model Processes for Pyrolysis of Solid Fuels. Industrial \& Engineering Chemistry Research. 2013;52:14376-83.

[59] Várhegyi G, Bobály B, Jakab E, Chen H. Thermogravimetric study of biomass pyrolysis kinetics. A distributed activation energy model with prediction tests. Energy \& Fuels. 2013;25:24-32.

[60] Lédé J. Biomass pyrolysis: Comments on some sources of confusions in the definitions of temperatures and heating rates. Energies. 2010;3:886-98.

[61] Jess A, Andresen A-K. Influence of mass transfer on thermogravimetric analysis of combustion and gasification reactivity of coke. Fuel. 2010;89:1541-8.

[62] Pazó JA, Granada E, Saavedra A, Eguía P, Collazo J. Biomass thermogravimetric analysis: Uncertainty determination methodology and sampling maps generation. International Journal of Molecular Sciences. 2010;11:2701.

[63] Cai J, Liu R. Research on water evaporation in the process of biomass pyrolysis. Energy \& Fuels. 2007;21:3695-7.

[64] Cai J, Chen S. Determination of drying kinetics for biomass by thermogravimetric analysis under nonisothermal condition. Drying Technology. 2008;26:1464-8.

[65] Valente M, Brillard A, Schönnenbeck C, Brilhac J-F. Investigation of grape marc combustion using thermogravimetric analysis. Kinetic modeling using an extended independent parallel reaction (EIPR). Fuel Processing Technology. 2015;131:297-303. [66] Chen D, Zheng Y, Zhu X. In-depth investigation on the pyrolysis kinetics of raw biomass. Part I: Kinetic analysis for the drying and devolatilization stages. Bioresource Technology. 2013;131:40-6.

[67] ASTM E1131 - 08. Standard Test Method for Compositional Analysis by Thermogravimetry. West Conshohocken, PA: ASTM International; 2014.

[68] Vyazovkin S, Wight CA. Kinetics in solids. Annual Review of Physical Chemistry. 1997;48:125-49.

[69] Brachi P, Miccio F, Miccio M, Ruoppolo G. Pseudo-component thermal decomposition kinetics of tomato peels via isoconversional methods. Fuel Processing 
Technology. 2016;154:243-50.

[70] Cai J, Wu W, Liu R, Huber GW. A distributed activation energy model for the pyrolysis of lignocellulosic biomass. Green Chemistry. 2013;15:1331-40.

[71] Malik G. Calculus of Finite Difference \& Numerical Analysis: Krishna Prakashan Media; 2003.

[72] Vyazovkin S, Burnham AK, Criado JM, Pérez-Maqueda LA, Popescu C, Sbirrazzuoli N. ICTAC Kinetics Committee recommendations for performing kinetic computations on thermal analysis data. Thermochimica Acta. 2011;520:1-19.

[73] Simonoff JS. Smoothing Methods in Statistics: Springer New York; 2012.

[74] Vyazovkin S, Burnham AK, Criado JM, Pérez-Maqueda LA, Popescu C, Sbirrazzuoli N. ICTAC Kinetics Committee recommendations for performing kinetic computations on thermal analysis data. Thermochimica Acta. 2011;520:1-19.

[75] Tarrío-Saavedra J, López-Beceiro J, Naya S, Francisco-Fernández M, Artiaga R. Simulation study for generalized logistic function in thermal data modeling. Journal of Thermal Analysis and Calorimetry. 2014;118:1253-68.

[76] Adnađević B, Janković B, Kolar-Anić L, Minić D. Normalized Weibull distribution function for modelling the kinetics of non-isothermal dehydration of equilibrium swollen poly(acrylic acid) hydrogel. Chemical Engineering Journal. 2007;130:11-7.

[77] Cai J, Alimujiang S. Kinetic analysis of wheat straw oxidative pyrolysis using thermogravimetric analysis: Statistical description and isoconversional kinetic analysis. Industrial and Engineering Chemistry Research. 2009;48:619-24.

[78] Cheng Z, Wu W, Ji P, Zhou X, Liu R, Cai J. Applicability of Fraser-Suzuki function in kinetic analysis of DAEM processes and lignocellulosic biomass pyrolysis processes. Journal of Thermal Analysis and Calorimetry. 2015;119:1429-38.

[79] Perejón A, Sánchez-Jiménez PE, Criado JM, Pérez-Maqueda LA. Kinetic analysis of complex solid-state reactions. A new deconvolution procedure. Journal of Physical Chemistry B. 2011;115:1780-91.

[80] Svoboda R, Málek J. Applicability of Fraser-Suzuki function in kinetic analysis of 
complex crystallization processes. Journal of Thermal Analysis and Calorimetry. 2013;111:1045-56.

[81] Pintus E, Sorbolini S, Albera A, Gaspa G, Dimauro C, Steri R, et al. Use of locally weighted scatterplot smoothing (LOWESS) regression to study selection signatures in Piedmontese and Italian Brown cattle breeds. Animal Genetics. 2014;45:1-11.

[82] Härdie W, Lütkepohl H, Chen R. A review of nonparametric time series analysis. International Statistical Review. 1997;65:49-72.

[83] Simonoff JS. Three sides of smoothing: Categorical data smoothing, nonparametric regression, and density estimation. International Statistical Review. 1998;66:137-56.

[84] Chen HX, Liu NA, Shu LF, Zong RW. Smoothing and differentiation of thermogravimetric data of biomass materials. Journal of Thermal Analysis and Calorimetry. 2004;78:1029-41.

[85] Caballero JA, Conesa JA. Mathematical considerations for nonisothermal kinetics in thermal decomposition. Journal of Analytical and Applied Pyrolysis. 2005;73:85100.

[86] Wu W, Mei Y, Zhang L, Liu R, Cai J. Kinetics and reaction chemistry of pyrolysis and combustion of tobacco waste. Fuel. 2015;156:71-80.

[87] Bowman AW, Azzalini A. Applied Smoothing Techniques for Data Analysis: The Kernel Approach with S-Plus Illustrations: OUP Oxford; 1997.

[88] Bisgaard S, Kulahci M. Time Series Analysis and Forecasting by Example: Wiley; 2011.

[89] Bhattacharyya S. Handbook of Research on Advanced Hybrid Intelligent Techniques and Applications: IGI Global; 2015.

[90] Steffensen JF. Interpolation: Second Edition: Dover Publications; 2012.

[91] Hackbusch W. Interpolation. The Concept of Stability in Numerical Mathematics. Berlin, Heidelberg: Springer Berlin Heidelberg; 2014. p. 47-62.

[92] Sbirrazzuoli N, Vincent L, Mija A, Guigo N. Integral, differential and advanced isoconversional methods: Complex mechanisms and isothermal predicted conversion- 
time curves. Chemometrics and Intelligent Laboratory Systems. 2009;96:219-26.

[93] And SV, Wight CA. Isothermal and nonisothermal reaction kinetics in solids: In search of ways toward consensus. Journal of Physical Chemistry A. 1997;101:8279-84. [94] Janković B, Mentus S, Janković M. A kinetic study of the thermal decomposition process of potassium metabisulfite: Estimation of distributed reactivity model. Journal of Physics and Chemistry of Solids. 2008;69:1923-33.

[95] Allen MP. Understanding Regression Analysis: Springer US; 2007.

[96] Cortés AM, Bridgwater AV. Kinetic study of the pyrolysis of miscanthus and its acid hydrolysis residue by thermogravimetric analysis. Fuel Processing Technology. 2015;138:184-93.

[97] Hache F, Delichatsios M, Fateh T, Zhang J. Comparison of methods for thermal analysis: Application to PEEK and a composite PEEK+CF. Journal of Fire Sciences. 2015;33:232-46.

[98] Gai C, Dong Y, Zhang T. The kinetic analysis of the pyrolysis of agricultural residue under non-isothermal conditions. Bioresource Technology. 2013;127:298-305. [99] Greenhalf CE, Nowakowski DJ, Bridgwater AV, Titiloye J, Yates N, Riche A, et al. Thermochemical characterisation of straws and high yielding perennial grasses. Industrial Crops and Products. 2012;36:449-59.

[100] Wu K, Liu J, Wu Y, Chen Y, Li Q, Xiao X, et al. Pyrolysis characteristics and kinetics of aquatic biomass using thermogravimetric analyzer. Bioresource Technology. 2014;163:18-25.

[101] Chen T, Cai J, Liu R. Combustion kinetics of biochar from fast pyrolysis of pine sawdust: Isoconversional analysis. Energy Sources, Part A: Recovery, Utilization, and Environmental Effects. 2015;37:2208-17.

[102] Chen D, E S, Liu L. Analysis of pyrolysis characteristics and kinetics of sweet sorghum bagasse and cotton stalk. Journal of Thermal Analysis and Calorimetry. 2017:doi: 10.1007/s10973-017-6585-9.

[103] Vyazovkin S. A time to search: Finding the meaning of variable activation energy. Physical Chemistry Chemical Physics. 2016;18:18643-56. 
